NBER WORKING PAPER SERIES

\title{
CHAOS, SUNSPOTS, AND AUTOMATIC STABILIZERS
}

\author{
Lawrence J. Christiano \\ Sharon G. Harrison
}

NBER Working Paper 5703

\section{NATIONAL BUREAU OF ECONOMIC RESEARCH 1050 Massachusetts Avenue \\ Cambridge, MA 02138 \\ August 1996}

We have benefitted from discussions with Fernando Alvarez, Jess Benhabib, Michele Boldrin, V.V. Chari, Russell Cooper, Martin Eichenbaum, Ian Domowitz, Chris Gust, Nicola Persico, Michael Woodford, Randall Wright, and Michelle Zaharchuk, and we are grateful to Victor Valdivia for research assistance. Christiano is grateful to the National Science Foundation for financial support. This paper is part of NBER's research program in Economic Fluctuations and Growth. Any opinions expressed are those of the authors and not those of the Federal Reserve Bank of Minneapolis, the Federal Reserve System, or the National Bureau of Economic Research.

(C) 1996 by Lawrence J. Christiano and Sharon G. Harrison. All rights reserved. Short sections of text, not to exceed two paragraphs, may be quoted without explicit permission provided that full credit, including (C) notice, is given to the source. 


\title{
CHAOS, SUNSPOTS, AND AUTOMATIC \\ STABILIZERS
}

\begin{abstract}
We study a one-sector growth model which is standard except for the presence of an externality in the production function. The set of competitive equilibria is large. It includes constant equilibria, sunspot equilibria, cyclical and chaotic equilibria, and equilibria with deterministic or stochastic regime switching. The efficient allocation is characterized by constant employment and a constant growth rate. We identify an income tax-subsidy schedule that supports the efficient allocation as the unique equilibrium outcome. That schedule has two properties: (i) it specifies the tax rate to be an increasing function of aggregate employment, and (ii) earnings are subsidized when aggregate employment is at its efficient level. The first feature eliminates inefficient, fluctuating equilibria, while the second induces agents to internalize the externality.
\end{abstract}

Lawrence J. Christiano

Department of Economics

Northwestern University

2003 Sheridan Road

Evanston, IL 60208-2600

and NBER

lchrist@merle.acns.nwu.edu
Sharon G. Harrison

Department of Economics

Northwestern University

2003 Sheridan Road

Evanston, IL 60208-2600 


\section{Introduction}

Interest is growing in business cycle models with multiple, self-fulfilling rational expectations equilibria. ${ }^{1}$ These models offer a new source of impulses to business cycles-disturbances to expectations - and they offer new mechanisms for propagating and magnifying the effects of existing shocks, such as shocks to monetary policy, to government spending, and to technology. ${ }^{2}$ Although initial versions of these models appear to rely on empirically implausible parameter values, recent vintages are based on increasingly plausible empirical foundations. ${ }^{3}$

The policy implications of the new models differ sharply from those of current mainstream equilibrium models, which emphasize shifts to preferences and technology as the basic impulses to the business cycle. These models have been used to articulate the notion

\footnotetext{
${ }^{1}$ Influential early papers include Azariadis (1981), Bryant (1983), Cass and Shell (1983), Cooper and John (1988), Diamond (1982), Farmer and Woodford (1984), Shleifer (1986), and Woodford (1986b). The first paper to take seriously the quantitative predictions of a business cycle model with self-fulfilling expectations is Woodford (1988). Rational expectations models with multiple equilibria have attracted attention in other areas too. See Benhabib and Perli (1994), Krugman (1991), and Matsuyama (1991a) for a discussion in the context of international trade and growth. See Cole and Kehoe (1996) for an analysis of the Mexican debt crisis. See Bryant (1981) and Diamond and Dybvig (1983) for discussions in the context of models of banking. See Boldrin, Kiyotaki, and Wright $(1993)$ and Mortensen $(1989,1991)$ for discussions on dynamic models of search and matching.

${ }^{2}$ An extensive literature documents the inadequacy of propagation in standard business cycle models. See, for example, Burnside and Eichenbaum (1995), Christiano (1988, p. 269), Cogley and Nason (1995), Rotemberg and Woodford (1996), and Watson (1993). An early study showing how models with indeterminate equilibria provide increased magnification and propagation of monetary shocks is Farmer and Woodford (1984). More recent studies include Beaudry and Devereux (1994), Benhabib and Farmer (1996), Guesnerie and Woodford (1992), and Matheny (1994). For a recent argument that macroeconomists are short on shocks for accounting for the business cycle, see Cochrane (1995).

${ }^{3}$ For example, the models of Benhabib and Farmer (1994), Farmer and Guo (1994) and Gali (1994a,b) rely on increasing returns in production. (See Schmitt-Grohe 1995.) The results of subsequent empirical research suggested that the degree of increasing returns required for the Benhabib and Farmer and Farmer and Guo models to display sunspot equilibria is too high. (See Burnside, Eichenbaum, and Rebelo 1995 for one such effort, and see also Benhabib and Farmer 1995 for a review of several others.) These empirical results in turn stimulated further theoretical work: recently, Benhabib and Farmer (1995) showed that a twosector version of their model requires a much lower degree of increasing returns to guarantee the existence of sunspot equilibria.
} 
that economic fluctuations represent the economy's efficient responses to shocks and to cast doubt on the desirability of macroeconomic stabilization policy. ${ }^{4}$ In contrast, the new models suggest that institutional arrangements and policy rules designed to reduce fluctuations in output may be desirable. (See Grandmont 1986, Guesnerie and Woodford 1992, Shleifer 1986, Woodford 1986b,1991, and the articles in the symposium summarized in Woodford 1994. $)^{5}$

This paper pursues these ideas in a particular business cycle model. The model studied is a version of the one-sector, external increasing returns model recently studied by Baxter and King (1991), Benhabib and Farmer $(1994,1995)$, and Farmer and Guo $(1994,1995){ }^{6}$ Our version of this model has a significant advantage relative to the versions analyzed in the literature. In those, analysis of the global set of equilibria is typically quite difficult, and so researchers confine themselves to studying the set of equilibria that is local to the steady state. By contrast, the structure of our model is such that the global set of equilibria is transparent and can therefore easily be analyzed. It turns out that this set of equilibria is remarkably rich, and it includes sunspot equilibria, regime switching equilibria, and equilibria

\footnotetext{
${ }^{4}$ See Kydland and Prescott (1980) and Sargent $(1979$, p. 393) for a statement of the case that output stabilization is undesirable. The "preference and technology" literature on macroeconomics did not completely rule out the possibility that some forms of stabilization might be desirable. Researchers who incorporated frictions like price rigidities did see some role for activist policy. (See Fischer 1980.)

${ }^{5}$ An important early example of the potential stabilizing role of institutional arrangements occurs outside the area of business cycle analysis and is provided by the work of Bryant (1981) and Diamond and Dybvig (1983). They showed that a spontaneous burst of pessimism on the part of depositors could trigger socially inefficient bank runs and that a government policy-deposit insurance-could be designed that would eliminate this source of instability.

${ }^{6}$ As in these papers, we do not formally articulate what the source of external increasing returns is. Examples of analyses that are explicit about the nature of external effects include Dianond (1982), Howitt and McAfee (1988), and Romer (1986). Benhabib and Farmer (1994) suggest the possibility that there is a way of reformulating our model so that the source of increasing returns is internal to the firm, while leaving our basic analysis unaffected. The analysis in Romer (1987) suggests yet another possibility: that the increasing returns may actually reflect gains from specialization. We have not yet explored these possibilities.
} 
which appear chaotic. Our analysis illustrates the potential pitfalls of focusing only on the equilibria that are local to some steady state.

We establish that the set of bounded solutions to a particular expectational difference equation corresponds to equilibria for our model. This set is simple to characterize because the difference equation is only first order and has a simple analytic representation. This is true, despite the fact that capital accumulation and employment are endogenous in the model. An important feature of the difference equation is that for every initial condition, it has two solutions. This two-branch feature of the Euler equation is an important reason the set of equilibria for the model includes regime switching equilibria of the type studied by Hamilton (1989) and equilibria that appear chaotic. ${ }^{7}$

Even the efficient allocations in our model are straightforward to determine, despite the lack of convexity in the aggregate resource constraint set due to the externality. The efficient allocations are unique and involve no fluctuations.

We examine the operating characteristics of two automatic stabilizer tax regimes. Each has the property that the income tax rate rises if the economy moves into a boom and falls if it goes into a recession. Under each tax regime, the economy has a unique interior equilibrium, in which output is constant. However, one tax regime stabilizes output on an inefficient level of output, and the other stabilizes output on the efficient allocations. We show that implementing the first tax regime may increase, or even decrease, welfare. ${ }^{8}$ We

\footnotetext{
${ }^{7}$ For other examples of a "branching" Euler equation in infinite horizon growth models, see Benhabib and Perli (1994) and Benhabib and Rustichini (1994).

${ }^{8}$ This possibility has been discussed by Guesnerie and Woodford (1992, pp. 383-388), Shleifer (1986), and Woodford (1991, p. 103) in other contexts.
} 
establish two things about designing a tax system that supports the efficient allocations as the unique interior equilibrium. First, such a system must specify that the tax rate vary with the level of aggregate economic activity. When the tax rate is specified to be a fixed constant, then there is more than one equilibrium, with the efficient one being only one of them. Second, the efficient equilibrium in this case is determinate, so that a standard local analysis of the set of equilibria would falsely conclude that only one equilibrium is possible. These results draw attention to the importance of the proper design of automatic stabilizer tax systems and point to a potential pitfall in the traditional approach to policy design, which tends to focus on minimizing output variance. ${ }^{9}$ These results also illustrate the potential dangers of the standard practice of focusing exclusively on local equilibria.

Finally, our model provides a convenient vehicle for articulating some econometric issues that arise in the analysis of models with multiple equilibria. As emphasized by Woodford (1991, p. 77), there is a widespread perception that "anything goes" with sunspot modelsany set of facts can be explained. The model in this paper can be used to illustrate that sunspot models in principle do impose discipline on an empirical analysis. ${ }^{10}$ With one exception, the econometric procedures used to analyze standard models with unique equilibria and driven by exogenous shocks can be used to analyze and test sunspot models too. The exception is that procedures which select parameter values by equating model first moments and corresponding sample first moments may no longer be well-defined. This is because

\footnotetext{
${ }^{9}$ An influential example is the analysis of Poole (1970), who argues that the appropriate choice of monetary policy regime depends on whether shocks emanate from financial markets or investment decisions. The criterion driving the policy design in Poole's analysis is minimization of output variance.

${ }^{10}$ See Dagsvik and Jovanovic (1994), Farmer and Guo (1995), Imrohoroglu (1993), Jovanovic (1989), Sargent and Wallace $(1987)$, and Woodford $(1987,1988,1991)$ for further development of this point.
} 
there may be a set of possible first moments associated with any parameter configuration, depending on which equilibrium the economy is in.

The intuition underlying the dynamics in our model is essentially the same as that described by Benhabib and Farmer (1994) and Farmer and Guo (1994). The economy is perfectly competitive, and individual producers have linearly homogeneous production functions in capital and labor, which are strictly concave in each. However, economywide average output operates as an externality in front of each firm's production function, shifting it up when average output is high. The latter is the key to why there are multiple equilibria in our model and to why expectations can act as an independent source of fluctuations. If all households act on the conjecture that the current period's wage rate is high by supplying more labor services to the market, then the market-clearing wage is high because of the externality on labor. Similarly, if households act on the conjecture that next period's rental rate on capital is high by buying more investment goods today, then their conjecture will be validated. ${ }^{11}$

A regime which specifies that the tax rate rises with aggregate employment has the potential to stabilize output by defeating the mechanism that gives rise to multiple equilibria. Conjectures that the rate of return on market activity is high cannot be self-fulfilling if the

\footnotetext{
${ }^{11}$ This is the case for two reasons. First, the externality on capital prevents next period's increase in capital from directly reducing the marginal product of capital. (That the externality is strong enough for the aggregate capital stock not to enter the marginal product of capital is the reason the difference equation mentioned above is first order, which in turn is the reason the global set of equilibria is transparent in our model.) Second, the externality on labor helps ensure that the increase in next period's wage rate, occasioned by the rise in capital next period, stimulates a large increase in employment. This indirectly helps drive up next period's rental rate on capital.
} 
proceeds are taxed away. ${ }^{12}$

The outline of the paper is as follows. Our model and equilibrium concept are presented in Section 2. Section 3 establishes our characterization result for the set of competitive equilibria. Sections 4 and 5 analyze the deterministic and stochastic equilibria of the model, respectively. Econometric issues are addressed in the context of the analysis of stochastic equilibria. Section 6 considers the impact of an automatic stabilizing tax policy and reports the socially optimal allocations. Section 7 concludes.

\section{The Model}

Let $s_{t}$ denote the realization of the exogenous shocks at date $t$. In models with shocks to fundamentals, $s_{t}$ would include shifts to preferences or technology, or to government spending. In this paper, we do not consider such shocks. In the stochastic versions of our model, $s_{t}$ represents disturbances which influence equilibrium outcomes, but which do not affect fundamentals. We let $s^{t}=\left(s_{0}, s_{1}, \ldots, s_{t}\right)$ denote a history of realizations up to and including date $t$. For simplicity, we only consider environments in which the number of possible values of $s_{t}$ is finite for each $t$. The probability of history $s^{t}$ is denoted $\mu_{t}\left(s^{t}\right)$. To conserve on notation, from here on we delete the subscript $t$ on $\mu$. This should not cause confusion: that the functions $\mu_{t}\left(s^{t}\right)$ and $\mu_{r}\left(s^{r}\right), r \neq t$ are different is evident from the fact that the quantity of elements in $s^{t}$ and $s^{T}$ is different. We adopt this notational

\footnotetext{
${ }^{12} \mathrm{Our}$ argument is related to the one in Schmitt-Grohe and Uribe (1996). They show that a procyclical tax policy (designed to support a balanced budget) can destabilize the economy by making possible sunspot equilibria.
} 
convention for all functions of histories. The probability of $s^{t+1}$ conditional on $s^{t}$ is denoted $\mu\left(s^{t+1} \mid s^{t}\right) \equiv \mu_{t+1}\left(s^{t+1}\right) / \mu_{t}\left(s^{t}\right)$. We now discuss the agents in our model and our concept of equilibrium.

\subsection{Households}

We assume a large number of identical households. At each $s^{t}$ and $t$, the representative household values consumption and leisure henceforth according to the following utility function:

$$
\sum_{j=t}^{\infty} \sum_{s^{j} \mid s^{\iota}} \beta^{j-t} \mu\left(s^{j}\right) u\left[c\left(s^{j}\right), n\left(s^{j}\right)\right]
$$

where $\beta \epsilon(0,1)$ is the discount rate, $s^{j} \mid s^{t}$ denotes histories, $s^{j}$, that are continuations of the given history, $s^{t}$, and $c\left(s^{j}\right), n\left(s^{j}\right)$ denote consumption and labor, respectively, conditional on history $s^{j}$. The household must respect the following sequence of budget constraints:

$$
\begin{aligned}
c\left(s^{j}\right)+k\left(s^{j}\right)-(1-\delta) k\left(s^{j-1}\right) & = \\
{\left[1-\tau\left(s^{j}\right)\right]\left[r\left(s^{j}\right) k\left(s^{j-1}\right)+w\left(s^{j}\right) n\left(s^{j}\right)\right]+T\left(s^{j}\right), \text { all } s^{j} \mid s^{t}, j } & \geq t
\end{aligned}
$$

where $r\left(s^{j}\right)$ and $w\left(s^{j}\right)$ denote the market rental rate on capital and the wage rate, respectively. Also, $\tau\left(s^{j}\right)$ is the tax rate on income, $T\left(s^{j}\right)$ denotes lump-sum transfers from the government, and $k\left(s^{j}\right)$ denotes the stock of capital at the end of period $j$, given history $s^{j}$. The household also takes $k\left(s^{t-1}\right)$ as given at $s^{t}$. Finally, the household must satisfy the 
following inequality constraints:

$$
k\left(s^{j}\right) \geq 0, c\left(s^{j}\right) \geq 0,0 \leq n\left(s^{j}\right) \leq 1
$$

for all $s^{j} \mid s^{t}$ and $j \geq t$ and takes as given and known the actual future date-state contingent prices and taxes:

$$
\left\{r\left(s^{j}\right), w\left(s^{j}\right), \tau\left(s^{j}\right), T\left(s^{j}\right) ; j \geq t, \text { all } s^{j} \mid s^{t}\right\}
$$

We assume that

$$
u(c, n)=\log c+\sigma \log (1-n)
$$

where $\sigma>0$.

Formally, at each $s^{t}$ and $t$, the household problem is to choose $\left\{c\left(s^{j}\right), n\left(s^{j}\right), k\left(s^{j}\right) ; j \geq t\right.$, all $\left.s^{j} \mid s^{t}\right\}$ to maximize (2.1) subject to (2.2), (2.3), (2.4), and the initial stock of capital, $k\left(s^{t-1}\right)$. The intertemporal Euler equations corresponding to this problem are

$$
u_{c}\left(s^{j}\right)=\beta \sum_{s^{j+1} \mid s^{t}} \mu\left(s^{j+1} \mid s^{j}\right) u_{c}\left(s^{j+1}\right)\left\{\left[1-\tau\left(s^{j+1}\right)\right] r\left(s^{j+1}\right)+1-\delta\right\}
$$

all $s^{j} \mid s^{t}, j \geq t$, and the intratemporal Euler equations are

$$
\frac{-u_{n}\left(s^{j}\right)}{u_{c}\left(s^{j}\right)}=\left[1-\tau\left(s^{j}\right)\right] w\left(s^{j}\right), \text { all } s^{j} \mid s^{t}, j \geq t
$$

Here, $u_{\mathrm{c}}\left(s^{j}\right)$ and $u_{n}\left(s^{j}\right)$ denote the partial derivatives of $u$ with respect to its first and second 
arguments, evaluated at $c\left(s^{j}\right), n\left(s^{j}\right)$. Finally, the household's transversality condition is

$$
\lim _{T \rightarrow \infty} \beta^{T} \sum_{s^{T} \mid s^{\mathrm{e}}} \mu\left(s^{T} \mid s^{t}\right) u_{c}\left(s^{T}\right) k\left(s^{T}\right)=0 .
$$

The sufficiency of the Euler equations, (2.6) and (2.7), and transversality condition, (2.8), for an interior solution to the household problem may be established by applying the proof strategy for Theorem 4.15 in Stokey and Lucas with Prescott (1989).

\subsection{Firms}

We assume a large number of identical firms, each of which solves a static problem at every $s^{t}$. As a result, we can, without risking confusion, simplify the notation by deleting the $s^{t}$ notation. The representative firm faces the following technology relating its output, $Y$, to its capital, $K$, and labor, $N$, inputs and to the economywide average level of output, $y$ :

$$
Y=f(y, K, N)=y^{\gamma} K^{\alpha} N^{(1-\alpha)}, 0 \leq \gamma, \alpha \leq 1 .
$$

We assume that

$$
\alpha=1-\gamma
$$

The relation between the economywide average level of output and the economywide average stock of capital, $k$, and labor, $n$, is obtained by solving $y=f(y, k, n)$ for $y$ :

$$
y=k^{\alpha /(1-\gamma)} n^{(1-\alpha) /(1-\gamma)}=k n^{\frac{\gamma}{1-\gamma}}
$$


given (2.10). The linearity of this function in terms of $k$ is essential for simplifying the analysis to come. In addition, as discussed by Rebelo (1991), linearity allows for growth to occur endogenously.

The firm takes $y, r$, and $w$ as given and chooses $K, N$ to maximize profits:

$$
Y-r K-w N
$$

subject to (2.9). The firms' first-order conditions for labor and capital are

$$
f_{N}=w, f_{K}=r
$$

where $f_{K}$ and $f_{N}$ are the derivatives of $f$ with respect to its second and third arguments, respectively. We assume firms behave symmetrically, so that consistency requires $y=Y, k=$ $K, n=N$. Imposing these, we get

$$
f_{N}=(1-\alpha) n k, f_{K}=\alpha n^{2}
$$

with $\gamma=2 / 3$. With this value of $\gamma$, the model implies that labor's share is $2 / 3$, which is close to the value estimated using the national income and product accounts (Christiano 1988). 


\subsection{Government}

The income tax rate policy, $\tau\left(s^{t}\right)$, is specified exogenously, and we require that the following budget constraint be satisfied for each $s^{t}$ :

$$
\tau\left(s^{t}\right)\left[r\left(s^{t}\right) k\left(s^{t-1}\right)+w\left(s^{t}\right) n\left(s^{t}\right)\right]=T\left(s^{t}\right)
$$

\subsection{Equilibrium}

The resource constraint for this economy is

$$
c\left(s^{t}\right)+k\left(s^{t}\right)-(1-\delta) k\left(s^{t-1}\right) \leq k\left(s^{t-1}\right) n\left(s^{t}\right)^{2}=y\left(s^{t}\right) .
$$

We then have ${ }^{13}$

Definition 2.1. A sequence-of-markets equilibrium is a set of prices $\left\{r\left(s^{t}\right), w\left(s^{t}\right)\right.$; all $s^{t}$, all $t \geq 0\}$, quantities $\left\{y\left(s^{t}\right), c\left(s^{t}\right), k\left(s^{t}\right), n\left(s^{t}\right)\right.$; all $s^{t}$, all $\left.t \geq 0\right\}$, and a tax policy $\left\{\tau\left(s^{t}\right), T\left(s^{t}\right)\right.$; all $\left.s^{t}, t \geq 0\right\}$ with the following four properties for each $t, s^{t}$ :

- Given the prices, the quantities solve the household's problem.

- Given the prices and given $\left\{y\left(s^{t}\right)=k\left(s^{t-1}\right) n\left(s^{t}\right)^{2}\right\}$, the quantities solve the firm's problem.

- The government's budget constraint is satisfied.

- The resource constraint is satisfied.

We find it useful to define an interior equilibrium. This is a sequence-of-markets equilibrium in which $a \leq n\left(s^{t}\right) \leq b$ for all $s^{t}$ for some $a$ and $b$ satisfying $0<a \leq b<1$.

\footnotetext{
${ }^{13}$ It is easily verified that the analysis would have been unaltered had we instead adopted the date 0 , Arrow-Debreu equilibrium concept. In this case, households would have had access to complete contingent claims markets.
} 


\section{Characterizing Equilibrium}

In the next section of the paper, we study deterministic equilibria in which prices and quantities do not vary with $s_{t}$ and stochastic (sunspot) equilibria in which prices and quantities do vary with $s_{t}$. The analysis of these equilibria is made possible by a characterization result, which is presented next.

Substituting (2.13) and (2.14) into the household's intertemporal Euler equation, (2.6), we get

$$
\frac{1}{\tilde{c}\left(s^{t}\right)}=\beta \frac{1}{\lambda\left(s^{t}\right)} \sum_{s^{t+1} \mid s^{t}} \mu\left(s^{t+1} \mid s^{t}\right) \frac{1}{\bar{c}\left(s^{t+1}\right)}\left\{\left[1-\tau\left(s^{t+1}\right)\right] \alpha n\left(s^{t+1}\right)^{2}+1-\delta\right\}
$$

where

$$
\tilde{c}\left(s^{t}\right)=\frac{c\left(s^{t}\right)}{k\left(s^{t-1}\right)}, \lambda\left(s^{t}\right)=\frac{k\left(s^{t}\right)}{k\left(s^{t-1}\right)}
$$

Substituting (2.14) into the household intratemporal Euler equation, (2.7), we get

$$
\tilde{c}\left(s^{t}\right)=\left[1-\tau\left(s^{t}\right)\right] \frac{\gamma}{\sigma} n\left(s^{t}\right)\left[1-n\left(s^{t}\right)\right]
$$

The resource constraint implies that

$$
\bar{c}\left(s^{t}\right)=n\left(s^{t}\right)^{2}+1-\delta-\lambda\left(s^{t}\right)
$$

Combining the two Euler equations, (3.1) and (3.3), and the resource constraint, (3.4), our 
system collapses into a single equation in current and next period's employment:

$$
\sum_{s_{t+1}} \mu\left(s^{t+1} \mid s^{t}\right) v\left[n\left(s^{t}\right), n\left(s^{t+1}\right) ; \tau\left(s^{t+1}\right)\right]=0, \text { all } s^{t}, t \geq 0
$$

where $v$ is

$$
v\left(n, n^{\prime} ; \tau^{\prime}\right)=\frac{1}{n^{2}+1-\delta-\lambda}-\frac{\beta\left[\left(1-\tau^{\prime}\right) \alpha\left(n^{\prime}\right)^{2}+1-\delta\right]}{\lambda\left[\left(n^{\prime}\right)^{2}+1-\delta-\lambda^{\prime}\right]}
$$

with

$$
\lambda=n^{2}+1-\delta-(1-\tau) \frac{\gamma}{\sigma} n(1-n) .
$$

Here, a ' denotes next period's value of the variable. The transversality condition, (2.8), is equivalent to

$$
\lim _{T \rightarrow \infty} \sum_{s^{T}} \beta^{T} \mu\left(s^{T}\right) \frac{\left[n\left(s^{T}\right)^{2}+1-\delta-\left[1-\tau\left(s^{T}\right)\right] \frac{\gamma}{\sigma} n\left(s^{T}\right)\left[1-n\left(s^{T}\right)\right]\right]}{\left.\left[1-\tau\left(s^{T}\right)\right]\right]_{\sigma}^{\gamma} n\left(s^{T}\right)\left[1-n\left(s^{T}\right)\right]}=0 .
$$

The basic equilibrium characterization result for this economy is

Proposition 3.1. Suppose that $\tau\left(s^{t}\right) \equiv 0$. If, for all $s^{t}$ and $t \geq 0$,

$$
\left\{n\left(s^{t}\right)\right\} \text { satisfies (3.5) }
$$

and

$$
a \leq n\left(s^{t}\right) \leq b \text { for some } 0<a \leq b<1
$$

then $\left\{n\left(s^{t}\right)\right\}$ corresponds to an equilibrium.

Proof. To establish the result, we need to compute the remaining objects-prices and quantities-in an equilibrium and verify that they satisfy (2.6), (2.7), (2.8), (2.13), and (2.16). A candidate set of objects is found in the obvious way. The sufficiency of the firstorder and transversality conditions for household optimization and the sufficiency of the first-order conditions for firm optimization guarantee that these are an equilibrium. 
The characterization result indicates that understanding the equilibria of the model requires understanding the $v$ function. It is easily confirmed that $v=\omega$ defines a quadratic function in $n^{\prime}$ for each fixed $n, \omega$. (Later, we refer to $\omega$ as the Euler error.) Hence, for each $n, \omega$ there are two possible $n^{\prime}: n^{\prime}=f_{u}(n, \omega)$ and $n^{\prime}=f_{l}(n, \omega)$, where

$$
\begin{aligned}
& f_{u}(n, \omega)=\frac{1}{2}\left\{b(n, \omega)+\sqrt{b(n, \omega)^{2}-4 c(n, \omega)}\right\} \\
& f_{l}(n, \omega)=\frac{1}{2}\left\{b(n, \omega)-\sqrt{b(n, \omega)^{2}-4 c(n, \omega)}\right\}
\end{aligned}
$$

Here,

$$
\begin{aligned}
b(n, \omega) & =\frac{\varphi(n) q(n, \omega)}{\alpha+q(n, \omega) \varphi(n)}, c(n, \omega)=\frac{1-\delta}{\alpha+q(n, \omega) \varphi(n)} \\
\varphi(n) & =\frac{n^{2}+1-\delta-\frac{\gamma}{\sigma} n(1-n)}{\beta n(1-n)} \\
q(n, \omega) & =1-\frac{\gamma}{\sigma} n(1-n) \omega .
\end{aligned}
$$

The function $v$ has the shape of a saddle, as can be seen in Figure 1a. The intersection of $v$ and the zero plane $(\omega=0)$ is depicted in Figure 1a as the boundary between the light and dark region of $v$. This intersection defines the curves $f_{u}(\cdot, 0)$ and $f_{l}(\cdot, 0)$, which are shown in Figure 1b. We refer to these as the upper and lower branches of the function $v$. The lower branch intersects the 45-degree line at two points, which are denoted $\bar{n}^{1}$ and $\bar{n}^{2}$. These intersection points cannot be seen in Figure 1b, but can be seen in Figure 1c, which displays $n^{\prime}-n$ for $n$ near the origin. It is easy to see from Figure 1a that with higher values of $\omega, f_{l}$ increases and $f_{u}$ decreases. The figure also indicates that for these functions to be 
real-valued, $\omega$ must not be too big.

The branches in the figure are computed using our baseline parameterization, $\sigma=2$, $\beta=1.03^{-\frac{1}{4}}, \delta=0.02$. Here, $\bar{n}^{1}=0.02$ and $\bar{n}^{2}=0.31$. The gross growth rates of capital (that is, $\lambda$ ) at these two points are 0.973 and 1.004 , respectively. Our assigned value of $\beta$ is often used in the real business cycle literature. The value of $\alpha$ causes the model's implication for the share of income going to capital and labor to coincide with one estimate of this quantity based on the national income and product accounts. (See, for example, Christiano 1988.) In addition, this parameterization of $\alpha$ facilitates some of the analytic results described above. However, we have verified that the shape of the $v$ function is not very sensitive to the perturbations in $\alpha$. The assigned value of $\delta$ can be justified based on our model's capital accumulation equation and on U.S. capital stock and investment data. (See, for example, Christiano 1988 and Christiano and Eichenbaum 1992.) The issue of how data may be brought to bear to determine a value of $\sigma$ is addressed below.

\section{Deterministic Equilibria}

We begin by considering deterministic equilibria, in which prices and quantities depend on $t$, but not on $s_{t}$. To simplify the presentation, we drop the history notation, and we use the conventional time subscript notation instead. As we shall see, the set of deterministic equilibria is quite rich. For example, any constant sequence $\left\{n_{t}\right\}$, with $n_{t}=\bar{n}^{1}$ or $n_{t}=\bar{n}^{2}$, satisfies the conditions of the characterization result and so is an equilibrium. Similarly, any

sequence with $n_{0} \in\left(\bar{n}^{1}, \tilde{n}\right)$ and $n_{t+1}=f_{l}\left(n_{t}, 0\right), t \geq 0$ is also an equilibrium, with $n_{t} \rightarrow \bar{n}^{2}$. 
Here, $\tilde{n}$ satisfies $\tilde{n}>\bar{n}^{2}$ and $\bar{n}^{1}=f_{l}(\tilde{n}, 0)$. Figure 2 exhibits two equilibrium paths, one starting with $n_{0}=0.4$ and the other with $n_{0}=0.2$. Each path converges monotonically to $\bar{n}^{2}$.

Other deterministic equilibria are more exotic and display a variety of types of regime switching. For example, the equilibrium employment policy function could be time nonstationary, with employment determined by the lower branch for, say, six periods, followed by a single-period jump to the upper branch, followed by another six-period sojourn on the lower branch, and so on. The model has another type of regime switching equilibrium too, in which the employment policy function is discontinuous.

As an example of the latter, consider equilibria in which employment, $n^{\prime}$, is determined by the upper branch for $n$ over one set of intervals in $(0,1)$ and by the lower branch over the complement of these intervals. One example of this is given by

$$
n^{\prime}=f(n), \text { where } f(n) \equiv\left\{\begin{array}{ccc}
f_{u}(n, 0) & \text { for } & n \leq \bar{n}^{1} \\
f_{l}(n, 0) & \text { for } & \bar{n}^{1}<n \leq m^{1} \\
f_{u}(n, 0) & \text { for } & m^{1}<n \leq m^{2} \\
f_{l}(n, 0) & \text { for } & m^{2}<n
\end{array}\right.
$$

where $m^{1}<\bar{n}^{2}$ and $m^{2}$ are a chosen set of numbers. By considering different values of $\sigma$, (4.1) defines a family of maps. As we shall see, there are elements in this family of maps which exhibit characteristics that resemble chaos. ${ }^{14}$ There are several concepts of chaos in

\footnotetext{
${ }^{14}$ For other discussions of chaos, with economic examples, see Boldrin and Woodford (1990) and Matsuyama (1991b).
} 
the literature. We consider two.

\subsection{Topological Chaos}

We consider the topological concept of chaos as discussed in Devaney (1989). We require two definitions first:

Definition 4.1. The map $f: J \rightarrow J$ is said to be topologically transitive if for any pair of open sets, $U, V \subset J$, there exists $k>0$ such that $f^{k}(U) \cap V \neq \emptyset$.

Here, $f^{1}(n)=f(n), f^{2}(n)=f[f(n)]$, and so on. Loosely, the above definition says that for almost all initial conditions, iterations on the map, $f$, produce an orbit (that is, $\left.n, f(n), f^{2}(n), \ldots\right)$ that visits every region, no matter how small, of $J$. An example of a map that violates this condition is the policy function of the standard one-sector growth model. For any initial capital stock, iterations on the policy function generate a sequence that converges monotonically to the steady state. If the initial capital stock is below the steady state, then capital stocks smaller than the initial condition and above steady state are not visited. A second definition that is important is

Definition 4.2. The map $f: J \rightarrow J$ has sensitive dependence on initial conditions if there exists $\delta>0$ such that, for any $n \in J$ and any neighborhood $N$ of $n$, there exists $y \in N$ and $m \geq 0$ such that $\left|f^{m}(n)-f^{m}(y)\right|>\delta$.

This says that for any initial condition, $n$, and any neighborhood, no matter how small, around $n$, there is at least one other initial condition whose orbit eventually differs by at least $\delta$ from the orbit of $n$. Note that the parameter $\delta$ is chosen as a function of the map, but it is not a function of $n$ or the size of the neighborhood around $n$. A sequence generated by a map that exhibits sensitivity to initial conditions is difficult to forecast for two reasons. 
First, the slightest measurement error in the initial conditions may result in a substantial error of forecast. Second, even if the initial conditions are measured accurately, then any slight rounding error in computing an orbit is likely to be magnified.

Then, we have

Definition 4.3. Let $J$ be a set. The map $f: J \rightarrow J$ is said to be chaotic on $J$ if

- $f$ has sensitive dependence on initial conditions.

- $f$ is topologically transitive.

- periodic points of $f$ are dense in $J$.

By a periodic point, $n$, we mean one for which there is some $k>0$ such that $n=f^{k}(n)$.

Theorems exist that establish conditions under which a given map is chaotic. Unfortunately, these theorems require either that $f$ be continuous (see, for example, chapter 1.1 of Devaney, 1989) or that it be piecewise continuous and differentiable with derivative greater than unity in absolute value. (See Lasota and Mackey, 1985, chapter 6.) We are not aware of theorems that include maps of the kind considered here. Instead, we follow the strategy pursued in Domowitz and El-Gamal $(1993,1994)$ and develop simulation-based evidence on whether our map is chaotic.

Consider sensitivity to initial conditions first. For this, we compute the Lyapunov coefficient, $L(n)$, associated with the map, $f$, defined in (4.1). The function, $L$, maps $n \in(0,1)$ into the real line. For any fixed $\tilde{n} \in(0,1)$,

$$
L(\tilde{n})=\lim _{T \rightarrow \infty} \frac{1}{T} \sum_{i=1}^{T} \log \left|\frac{d f\left(n_{i}\right)}{d n}\right|
$$


where $n_{i+1}=f\left(n_{i}\right), i=1, \ldots, T-1, n_{1}=\tilde{n}$, and $d f\left(n_{i}\right) / d n$ denotes the derivative of $f$ with respect to $n$, evaluated at $n=n_{i}$. To see why $L$ is of interest, note that the sum is equivalent to $\log \left|\frac{d f^{T}(\bar{n})}{d n}\right|$. If $\tilde{n}$ is a periodic point of any finite order $k$, then $f^{k}(\tilde{n})=\tilde{n}$. If it is a stable periodic point, then $\left|\frac{d f^{k}(\tilde{n})}{d n}\right|<1$. If $T=m k$, where $m$ is an arbitrary positive integer, then

$$
\frac{1}{T} \log \left|\frac{d f^{T}(\tilde{n})}{d n}\right|=\frac{1}{T} \log \left|\prod_{l=1}^{m} \frac{d f^{k}\left(n_{l}\right)}{d n}\right|=\frac{1}{k} \log \left|\frac{d f^{k}(\bar{n})}{d n}\right|<0
$$

where $n_{1}=\bar{n}$, and $n_{l+1}=f^{k}\left(n_{l}\right), l=1, \ldots, m-1$. This suggests that if $\bar{n}$ is a stable periodic point of any period, then $L(\tilde{n})$ must be negative. But if $f$ has a stable periodic point, or a point whose orbit intersects with such a point, then it violates sensitivity to initial conditions. Thus, a negative value of $L(n)$ indicates that one of the conditions necessary for $f$ to be chaotic fails. A positive value of $L(n)$ is a necessary condition for chaos.

Figure 3 shows $L(\tilde{n})$ for $\sigma$ in the range 1.25 to 2.20 , with $\tilde{n}$ fixed at $0.255 .{ }^{15}$ We truncated the infinite sum in (4.2) at $T=2,000$. We set $m^{1}=0.33, m^{2}=0.70$. Note that $L(\tilde{n})$ is positive for values of $\sigma$ less than 1.5. Hence, for values of $\sigma$ in this range, there is evidence that $f$ is characterized by sensitivity to initial conditions. To investigate this further, consider $\sigma=1.25$. Figures $4 \mathrm{a}$ and $4 \mathrm{~b}$ show two sequences of 400 observations on hours worked, simulated using $f$. In one case the initial condition is 0.455 , and in the other the initial condition is 0.454 . Despite the fact that the initial conditions are very close, the two orbits are quite different. In fact, they are eventually as dissimilar as they would have been had the

\footnotetext{
${ }^{15}$ In computational experiments not reported here, we found that the graph in Figure 3 is insensitive to the value of $\tilde{n}$. This insensitivity is consistent with results in Figure 5, discussed below.
} 
initial conditions been far apart. By the $70^{\text {th }}$ observation, the two series are completely out of phase. Then, by around the $310^{t h}$ observation, they are almost identical again. Although the amplitude of the two series varies somewhat, most of the differences between the two series has to do with phase. Note how strikingly different these equilibria are from the ones shown in Figure 2.

Now consider topological transitivity. One way to investigate this is to compute the histogram of orbits associated with different initial conditions. To compute this histogram, we divide the unit interval into 3,000 equal-width intervals and approximate the histogram of an orbit by the number of times hours worked lands in each interval in a simulation of length 50,000. Figure 5 shows histograms for orbits associated with four initial conditions drawn from very different parts of the unit interval. These histograms are similar in two respects. First, consistent with topological transitivity, each orbit appears to cover the same region of the unit interval. In particular, let $J$ denote the union of intervals with positive mass in Figure 5. Then $J$ appears to be independent of the initial conditions. This is consistent with the notion that orbits associated with almost all $n \in J$ wander through every small neighborhood of $J$. The second striking feature of the histograms in Figure 5 is that they appear to have the same shape. Thus, the histograms are consistent not only with the notion that almost all orbits in $J$ visit each subinterval in $J$ with positive probability (topological transitivity), but they are also consistent with the notion that the probability of visiting each subinterval is the same across orbits. 


\subsection{Statistical Chaos}

A second concept of chaos, closely related to the first, is statistical (Lasota and Mackey 1985). Here, we follow the treatment in Domowitz and El-Gamal $(1993,1994)$ and El-Gamal (1991).

Let $g$ be a density function defined on $J$. That is, $\int_{J} g(n) d n=1$ and $g(n) \geq 0$ for all $n \in J$. If we draw from $g$ and apply the map $f^{i}: J \rightarrow J$ to each draw, we have a new distribution of points on $J$. Denote this distribution by $f_{g}^{i}$. Then following Domowitz and El-Gamal $(1993,1994)$, we say that $f$ exhibits statistical chaos if $f_{g}^{i}$ exhibits the ergodic property or the mixing property.

Definition 4.4. The map $f: J \rightarrow J$ is ergodic if

$$
\lim _{T \rightarrow \infty} \frac{1}{T} \sum_{i=1}^{T} f_{g}^{i}=q, \text { for all } g \in G
$$

For regularity conditions on the limiting density function, $q$, and the set of density functions, $G$, see Domowitz and El-Gamal $(1993,1994)$. (Obviously, $G$ cannot include density functions which place mass exclusively on a single periodic point.) For $f$ to be ergodic does not actually require that $f_{g}^{i}$ settle down for large $i$. The mixing property does require this. Definition 4.5. The map $f: J \rightarrow J$ is mixing if

$$
\lim _{i \rightarrow \infty} f_{g}^{i}=q, \text { for all } g \in G
$$

The properties of ergodicity and mixing are closely related to the notions of topological transitivity and sensitive dependence. For example, consider a density function, $g$, which 
assigns positive probability to an arbitrarily selected and extremely small interval of initial conditions. Mixing requires that the orbits of these points eventually cover the same range in $J$ as if the initial conditions were instead drawn from a density that assigns positive probability to every subinterval of $J$.

We adopted the simulation-based approach of Domowitz and El-Gamal to investigate whether our $f$ map exhibits statistical chaos. Thus, we considered two $g$ functions. One places a uniform distribution on the interval $[0.16,0.32]$ and the other places a uniform distribution on the interval $[0.58,0.71]$. In each case, we drew 1,000 times from the $g$ function and computed $f^{3,000}$ for each draw. The resulting histograms are shown in Figure 6. There are two interesting features of these histograms. First, to the unaided eye they appear very similar to each other, consistent with the notion that $f$ satisfies the mixing condition. Still, the differences can be reasonably substantial, as the bottom graph in Figure 6 shows. Second, the histograms in Figure 6 closely resemble the orbit histograms shown in Figure 5. This suggests that our $f$ map approximately satisfies concepts of ergodicity in standard econometrics textbooks (for example, Hamilton 1994, pp. 46-47), in which statistical properties of individual sample realizations (that is, histograms of orbits) coincide with $q=\lim _{i \rightarrow \infty} f_{g}^{i}$.

\section{Sunspot Equilibria}

In this section, we study equilibria of our model in which prices and quantities respond to $s_{t}$. We construct two equilibria to illustrate the possibilities. The first, which we call 
a conventional sunspot equilibrium, uses $f_{l}$ only. This equilibrium is constructed near the deterministic steady state, $\bar{n}^{2}$, which, as noted above, has a continuum of deterministic equilibria which converge to it. Our choice of name reflects that this type of equilibrium is standard in the quantitative sunspot literature. ${ }^{16}$ The second equilibrium considered, which we call a regime switching sunspot equilibrium, involves stochastically switching between $f_{l}$ and $f_{u}$. Our analysis of these equilibria focuses on their welfare and business cycle properties. For this analysis, we find it useful to use the business cycle properties of U.S. data and of a standard real business cycle model as benchmarks. We conclude this subsection by making some observations about the econometrics of sunspot models in general and by discussing the empirical plausibility of our model.

\subsection{Conventional Sunspot Equilibrium}

In this equilibrium, $s \in R$ is independently distributed over time, with $s=-0.06$ and $s=0.06$ with probability $1 / 2$ each. These values for $s$ were chosen so that the equilibrium's implication for the standard deviation of Hodrick-Prescott detrended, logged equilibrium output coincides with the corresponding figure in the data. Given any $n$, next period's hours worked, $n^{\prime}$, is computed by first drawing $s$ and then solving

$$
n^{\prime}=f_{l}(n, s)
$$

\footnotetext{
${ }^{16}$ Because a continuum of other nonstochastic equilibria exists near the steady state equilibrium, $\bar{n}^{2}$, this equilibrium is said to be indeterminate (Boldrin and Rustichini 1994, p. 327). For a general discussion of the link between indeterminate equilibria and sunspots, see Woodford (1986a). Examples of quantitative analyses that construct sunspot equilibria in the neighborhood of indeterminate equilibria include Benhabib and Farmer (1994,1995), Farmer and Guo (1994,1995), and Gali $(1994 a, b)$.
} 
where $f_{l}$ is defined in (3.9). We set the initial level of hours worked, $n_{0}$, to $\bar{n}^{2}$. Recall that $\bar{n}^{2}$ is the higher of the two deterministic steady states associated with the lower branch, $f_{l}$. That is, of the two solutions to $x=f_{l}(x, 0), \bar{n}^{2}$ is the larger of the two.

To establish that this stochastic process for employment corresponds to an equilibrium, it is sufficient to verify that the conditions of the characterization result are satisfied. The first condition is satisfied by construction, and the second is satisfied because $n\left(s^{t}\right)$ remains within a compact interval that is a strict subset of the unit interval. That is, let $a$ be the smaller of the two values of $n$ that solve $a=f_{l}(a,-0.06)$, and let $b>a$ be the unique value of $n$ with the property $a=f_{l}(b,-0.06)$. Here, $a$ and $b$ are 0.0249 and 0.9509 after rounding. We verified that if $a \leq n \leq b$, then $a \leq n^{\prime} \leq b$ for $n^{\prime}=f_{l}(n,-0.06)$ and $n^{\prime}=f_{l}(n, 0.06)$. Thus, $\operatorname{prob}\left[a \leq n^{\prime} \leq b \mid a \leq n \leq b\right]=1$. It follows that $a \leq n\left(s^{t}\right) \leq b$ for all histories, $s^{t}$, with $\mu\left(s^{t}\right)>0$. The conditions of the characterization result are satisfied, and so we conclude that $n\left(s^{t}\right)$ corresponds to an equilibrium.

The first-moment properties of this equilibrium are reported in Table 1. They are similar to the corresponding properties of the U.S. data and of the real business cycle model. The second-moment properties of this equilibrium (see Table 3) also compare favorably with the corresponding sample analogs, at least relative to the performance of the real business cycle model (see Table 2). In this context, three observations are worth stressing. First, note the equilibrium's prediction that consumption is smooth relative to output and that productivity is roughly as volatile as hours worked. In the latter respect, the conventional sunspot equilibrium actually conforms more closely to the data than does the real business 
cycle model. The real business cycle model implies that productivity is about 65 percent more volatile than hours worked, whereas the conventional sunspot equilibrium implies that productivity is about as volatile as hours worked. In the data, productivity is about 30 percent less volatile than hours worked. Second, hours and productivity are both procyclical in the equilibrium, as they are in the data. The equilibrium's implication that productivity is procylical reflects the increasing returns in the model. Procyclical productivity helps account for the fact that equilibrium hours worked and consumption are both procyclical in the model. Finally, the model inherits a shortcoming of standard real business cycle models in overpredicting the correlation between productivity and hours worked. In the data, this quantity is essentially zero.

Some of these properties can also be seen by examining the plots in Figure 7. They are graphs of the logged and Hodrick-Prescott filtered data from the equilibrium described above. Consumption is smooth and investment is volatile in these graphs. In addition, hours worked and productivity are seen to be procyclical. Overall, this sunspot equilibrium compares quite well to the real business cycle model in its ability to mimic key features of postwar U.S. business cycles.

\subsection{Regime Switching Sunspot Equilibrium}

For this equilibrium, $s=[s(1), s(2)] \in R^{2}$, with $s(1) \in\{u, l\}$ and $s(2)=\omega \in\{-0.06,0.06\}$. We set the date 0 value of hours worked to $n\left(s_{0}\right)=\bar{n}^{2}$. We use the following recursive procedure to assign a level of employment to each history, $s^{t}$, that is logically possible, given the specified $s_{0}$. For any history, $s^{t}$, and associated level of employment, $n\left(s^{t}\right)$, let $n\left(s^{t+1}\right)$ be 
as follows:

$$
n\left(s^{t+1}\right)=f_{s_{t+1}(1)}\left(n\left(s^{t}\right), s_{t+1}(2)\right)
$$

for $t=1,2, \ldots$. We construct an equilibrium by devising a sequence of probabilities, $\mu\left(s^{t}\right)$, that assigns positive probability only to histories, $s^{t}$, for which $a \leq n\left(s^{t}\right) \leq b$, for some $a, b$ such that $0<a \leq b<1$. When the value of $s(1)$ changes along a history, we say there has been a regime switch.

Consider the following probabilities for $s_{t+1}(1)$ :

$$
\operatorname{prob}\left[s_{t+1}(1)=l\right]=\left\{\begin{array}{l}
0.9, \tilde{n}^{1}<n\left(s^{t}\right)<\tilde{n}^{2}, \tilde{n}^{1}=0.0370, \tilde{n}^{2}=0.9279 \\
1, \text { otherwise. }
\end{array}\right.
$$

Let $s(2)$ have the same distribution as $s$ in the previous equilibrium. We assume that the two elements of $s$ are independently distributed. Let $a$ and $b$ be defined as in the conventional sunspot equilibrium. We verified numerically that, under these circumstances, if $a \leq n\left(s^{t}\right) \leq b$, then $\operatorname{prob}\left[a \leq n\left(s^{t+1}\right) \leq b\right]=1$. It follows that, for all $s^{t}$ such that $\mu\left(s^{t}\right)>0$, $a \leq n\left(s^{t}\right) \leq b .{ }^{17}$ This establishes the second of the two conditions of the characterization result. To establish the first condition, note that by (5.2),

$$
v\left(n\left(s^{t}\right), n\left(s^{t+1}\right)\right)=s_{t+1}(2), \text { for all } s^{t}
$$

\footnotetext{
${ }^{17}$ Our specification of $\tilde{n}^{1}$ and $\tilde{n}^{2}$ is crucial for guaranteeing the second condition of the characterization result. For example, with $\tilde{n}^{1}=a$ and $\tilde{n}^{2}=b$, histories, $s^{t}$, in which hours worked fluctuate between values that approach 0 and 1 occur with high probability. With $\mu\left(s^{t}\right)$ specified in this way, the second condition of the characterization result fails.
} 
and by construction of the Euler error, $s_{t+1}(2)$,

$$
\sum_{s^{t+1} \mid s^{t}} \mu\left(s^{t+1} \mid s^{t}\right) s_{t+1}(2)=0, \text { for all } s^{t}
$$

This establishes that the conditions of the characterization result are satisfied, and we conclude that $n\left(s^{t}\right)$ corresponds to an equilibrium.

We now consider the dynamic properties of the regime switching sunspot equilibrium. First-moment properties are reported in Panel C of Table 1, while second-moment properties are reported in Panel B of Table 3. Regime switching is the key to understanding the dynamics of this equilibrium. Periodically, the economy switches to the upper branch, $f_{u}$, where employment is very high. The economy typically stays on the upper branch only briefly, and when it switches down again, employment drops to a very low level: near $a$. Employment then rises slowly until another switch occurs, when the economy jumps to the upper branch, and the process continues. The fact that the economy spends much time in the left region of the lower branch explains why average employment in this equilibrium is so low. This also explains why investment is, on average, negative. Regarding the secondmoment properties, output is substantially more volatile than it is in the data. Also, output displays very little serial correlation. The positive serial correlation produced by sojourns on the lower branch is offset by the negative serial correlation associated with transient jumps to the upper branch. These observations are supported by the time series plots of the logged, Hodrick-Prescott filtered data from this equilibrium, presented in Figure 8.

The regime switching equilibrium nicely illustrates a type of sunspot equilibrium that 
is possible. However, in contrast with the conventional sunspot equilibrium, the secondmoment properties of this equilibrium do not match the corresponding quantities in the data.

\subsection{Empirical Evaluation of the Model}

A variety of other econometric methods can be used to assess the empirical plausibility of this model..$^{18}$ One test of the model analyzes the fitted values of the sunspot shocks, $s$. Given values for the model parameters, these shocks can be recovered using employment data. ${ }^{19}$ For this test, we used the data on per capita, quarterly hours worked covering the period 1955Q3-1984Q1 studied in Christiano (1988) and Christiano and Eichenbaum (1992). The data, shown in Figure 9a, were converted into fractions of available time worked under the assumption that households' available time is 15 hours per day (1,369 hours per quarter). The fitted values of $s$ imply that all quarterly U.S. observations on hours worked lie on $f_{l}$, that is, $\hat{s}(1)=l$ throughout the sample. This complements the findings of the second-moment analysis reported above, which indicates that—within the confines of this model — regime switching does not improve our understanding of the aggregate data.

The time series on the fitted Euler equation error, $\hat{s}(2)$, are shown in Figure 9c. The model requires that this shock satisfy (5.5). All dynamic models have at least one orthogonality

\footnotetext{
${ }^{18}$ For a formal statistical approach to the moment comparison strategy for testing undertaken in the previous subsection, see the method based on the work of Hansen (1982) developed in Christiano and Eichenbaum (1992). This analysis integrates parameter uncertainty into evaluations of the "distance" between model and data second moments.

${ }^{19}$ For any two consecutive observations on employment, $n$ and $n^{\prime}, s(2)=v\left(n, n^{\prime}\right)$. Then, given $s(2)$, one finds the two values of $x, x_{l}<x_{u}$ such that $s(2)=v(n, x)$. If $n^{\prime}=x_{l}$, then $s(1)=l$, and $s(1)=u$ otherwise.
} 
condition like this. Generalized method of moments (GMM) procedures for testing it have been developed and applied extensively, beginning with the work of Hansen (1982) and Hansen and Singleton (1982). These tests focus on a model's implication that date $t+1$ Euler errors be orthogonal to all information available at date $t$, including a constant. The evidence in Figure 9c indicates that this test fails: the sample mean of the fitted Euler error is significantly negative $(-0.27)$, indicating that a nonzero constant is useful for predicting this variable. The second-moment properties of the fitted values of $\hat{s}(2)$ are more consistent with the theory. Figure $9 \mathrm{~b}$ shows the scatter plot of consecutive values of fitted Euler errors, and it suggests that the first-order autocorrelation of $\hat{s}(2)$ is not significantly different from zero. (The point estimate is -0.18 , with standard error $0.09^{20}$.) Figure $9 \mathrm{c}$ shows the scatter plot of the empirical measure of hours worked at date $t, n_{t}$, against the date $t+1$ fitted Euler error, $\hat{s}_{t+1}(2)$. Here too, the evidence does not imply a strong relationship between these variables. The point estimate of the correlation between these two variables is -0.20 , slightly more than twice the standard error of 0.09 . These results are subject to two caveats. First, they do not take into account sampling uncertainty in the estimated values of $\alpha$ and $\delta$. However, the results in Christiano and Eichenbaum (1992) suggest that this is very small and unlikely to change the results. Second, they are based on arbitrarily setting $\sigma=2$. A conventional GMM approach to this would select a value for $\sigma$ to ensure that sample analogs of the population orthogonality properties of the Euler errors are satisfied. For example, the value of $\sigma$ that sets the sample average of the fitted Euler errors to zero is $\hat{\sigma}=2.72$. Apart

\footnotetext{
${ }^{20}$ The standard error is $1 / \sqrt{115}$, where 115 is the number of observations in the sample.
} 
from changing the sample mean, this change in the value of $\sigma$ does not alter the properties of the Euler errors reported above.

We conclude that there is little evidence in the Euler errors against the model and that the upper branch appears not to be operative in the data.

Interestingly, conditional on ruling out the upper branch, $f_{u}$, the model implies a reduced form relation very much like the one found in standard models driven by fundamental shocks. For example, equation (5.1) closely resembles the equilibrium relation for employment implied by the general equilibrium model analyzed in Sargent $(1979$, p. 377$)$. The only qualitative difference is that in the latter, the shock variable, $s$, is a combination of disturbances to preferences and technology, while here it is a sunspot shock, $s(2)$. An implication is that the model can be estimated and tested using the same maximum likelihood strategies pursued in Altug (1989), Christiano (1988), Hall (1996), and McGrattan, Rogerson, and Wright (1996). This observation is consistent with the notion that sunspot models simply offer a new source of shocks. From an econometric perspective, they are not qualitatively different from models with fundamental shocks.

Our final test of the model focuses on its implications for the aggregate production technology, (2.11). To assess the plausibility of this formulation, we plot the log of output per unit of capital versus the log of per capita hours worked in Figure 10. (See the observations marked ${ }^{*}$.) The output and capital stock data used are the quarterly data covering the period 1955Q3-1984Q1 studied in Christiano (1988) and Christiano and Eichenbaum (1992). The data do indicate a positive relation, but it is not as strong as the one implied by the model, in 
which $\log (y / k)=2 \log (n)$. One way to assess the plausibility of the model is to compare this line with the least squares line fitted through the U.S. data points. A factor complicating the comparison with this data is that the model does not contain a theory of the error term in this relation-clearly one is needed, given the wide dispersion of the U.S. data points. Now, suppose the errors reflect technology shocks, which could easily be incorporated into the analysis. Then, assuming equilibrium labor responds positively to technology shocks, a standard simultaneity bias argument implies that the slope of the least squares line is biased upward, as an estimate of the power on hours worked in the aggregate production function. (See Klenow 1992.) Thus, conditional on interpreting the dispersion of data points in Figure 10 as reflecting the effects of technology shocks, we conclude that the data in that figure constitute a rejection of the very high power on hours worked in the production function of this paper..$^{21}$

To summarize the results so far, the analysis in this section shows that -at least in the context of our model-it is far from true that "anything goes" empirically with sunspot models. The models can be tested using standard econometric methods-GMM procedures for comparing sample and model-based second moments, GMM procedures for testing Euler equations, and standard maximum likelihood procedures. Although the conventional sunspot equilibrium does a surprisingly good job of accounting for business cycle phenomena, in the end, its strong increasing returns assumption is rejected by the data. ${ }^{22}$

\footnotetext{
${ }^{21}$ This complements findings in Burnside, Eichenbaum, and Rebelo (1995) and in the references they cite.

${ }^{22}$ For an attempt to extend our analysis to a version of the model with a smaller externality, see Guo and Lansing (1996).
} 


\subsection{Welfare Analysis}

We approximated the expected discounted utility for our equilibria using a Monte Carlo simulation method. For the conventional sunspot equilibrium and the regime switching sunspot equilibrium, the expected present discounted utilities are $-378.21(0.24)$ and $-570.58(1.77)$, respectively (numbers in parentheses are Monte Carlo standard errors). ${ }^{23}$ To understand the impact on utility of variance in the Euler error, $s(2)$, we also computed expected utility for a high variance version of our conventional sunspot equilibrium. In this case, $s(2) \in\{-0.55,0.55\}$. The expected present value of utility for this equilibrium is -363.35 (2.14). The present discounted level of utility associated with the constant employment deterministic equilibrium at $\bar{n}^{2}$ is -378.49 . We refer to this equilibrium as the constant employment equilibrium.

To compare these welfare numbers, we converted them to consumption equivalents. That is, we computed the constant percentage increase in consumption required in the constant employment equilibrium to make a household indifferent between that equilibrium and another given equilibrium. The results are shown in Table 4. They indicate that going from the constant employment equilibrium to the regime switching sunspot equilibrium is equivalent to a 289 percent permanent drop in consumption. Going to the conventional sunspot equilibrium is equivalent to a 0.9 percent permanent rise in consumption, and going to the high

\footnotetext{
${ }^{23}$ For each equilibrium, we drew 1,000 histories, $s^{t}$, each truncated to be of length 2,500 observations. Subject to the initial level of employment being $\bar{n}^{2}$ always, we computed consumption and employment along each history. For each equilibrium, we computed 1,000 present discounted values of utility, $v_{1}, \ldots, v_{1000}$. Our Monte Carlo estimate of expected present discounted utility, $v$, is the sample average of these: $\bar{v}=$ $\frac{1}{1000} \sum_{i=1}^{1000} v_{i}$. The fact that we use a finite number of replications implies that $\bar{v}$ is approximately normally distributed with mean $v$ and standard deviation $\sigma_{i} / \sqrt{1,000}$, where $\sigma_{i}$ is estimated by the standard deviation of $v_{1}, \ldots, v_{1000}$. We refer to $\sigma_{i} / \sqrt{1,000}$ as the Monte Carlo standard error.
} 
variance version of that equilibrium is equivalent to an 11.2 percent rise in consumption.

An interesting feature of these results is that, despite concavity in the utility function, increasing volatility in $s(2)$ raises welfare. This reflects a trade-off between two factors. First, other things being the same, a concave utility function implies that a sunspot equilibrium is welfare-inferior to a constant, deterministic equilibrium (concavity effect). However, other things are not the same. The increasing returns means that by bunching hard work, consumption can be increased on average without raising the average level of employment (bunching effect). When the volatility of the model economy with initial employment $\bar{n}^{2}$ is increased by raising the volatility of $s(2)$, then the bunching effect dominates the concavity effect. When volatility is instead increased by allowing regime switches, then the concavity effect dominates. In interpreting these results, it is important to recognize that they say nothing about the nature of the efficient allocations. All of the equilibria that we consider are inefficient, because of the presence of the externality in production.

\section{Policy Analysis}

We now consider the impact of various policies on the set of equilibria. We consider two countercyclical tax policies that reduce the set of interior equilibria to a singleton in that output is a constant. We refer to the first as a pure stabilizer because it does not distort margins in equilibrium. The second tax policy introduces just the right distortions so that the equilibrium supports the optimal allocations. We show that, for a tax policy to isolate the efficient allocations as a unique equilibrium, it is necessary that the tax rate vary in the 
right way with the state of the economy. For example, under a constant tax rate policy, the equilibrium is not unique. Interestingly, the equilibria are isolated in this case, so that they would escape detection under the usual procedure of analyzing local equilibria.

\subsection{A Pure Automatic Stabilizer}

In this section, we display a particular procyclical tax rate rule which reduces the set of equilibria to a singleton with $n_{t}=\bar{n}^{2}$ for all $t$ (the constant employment equilibrium). The tax policy has the property that in equilibrium, the tax rate is always zero and thus does not distort any margins. Given our previous results for the constant employment equilibrium, this tax rate rule improves welfare relative to the regime switching sunspot equilibrium, but actually reduces welfare relative to the conventional sunspot equilibrium. The possibility that stabilization of a sunspot by government policy might reduce welfare should not be surprising, given that both the sunspot equilibrium and the $\bar{n}^{2}$ equilibrium are inefficient.

Consider the following tax rate:

$$
\tau(n)=1-\frac{\bar{n}^{2}}{n}
$$

where $n$ denotes economywide average employment and $\bar{n}^{2}$ is the higher of the two nonstochastic steady state employment levels. (See Figure 1b.) Note that this tax rate is zero when aggregate employment is $\bar{n}^{2}$. It turns positive for higher levels of employment and negative for lower levels.

Let $\tilde{v}\left(n, n^{\prime}\right)$ denote (3.6) after substituting out for $\tau(n)$ from (6.1). It is easily verified 
that, for each value of $n$, there is at most one $n^{\prime}$ that solves $\tilde{v}\left(n, n^{\prime}\right)=0$. This is given by

$$
n^{\prime}=f(n)=\frac{\bar{n}^{2}-K(n)(1-\delta)}{\bar{n}^{2}[1+\alpha K(n)]}
$$

where

$$
K(n)=\frac{\beta \bar{n}^{2}}{\lambda(n)}(1-n), \lambda(n)=n^{2}+1-\delta-\frac{\gamma}{\sigma} \bar{n}^{2}(1-n)
$$

The function, $f$, and its derivative, $f^{\prime}$, have the property that at $n=1$,

$$
f(1)=1, f^{\prime}(1)=\beta\left[\frac{\alpha \bar{n}^{2}+1-\delta}{2-\delta}\right]<\beta
$$

since $\alpha \bar{n}^{2}<1$. Figure 11 shows $f$ under our baseline parameter values. For convenience, the two branches of $v=0, f_{u}$ and $f_{l}$, are also displayed.

There are three things worth emphasizing about $f$. First, it cuts the 45-degree line from below at $n=\bar{n}^{2}$, and it intersects the horizontal axis at a positive level of employment. This implies that there is no infinite sequence, $n_{t}, t=0,1,2, \ldots$, with $n_{0}<\bar{n}^{2}$ and $n_{t}=f\left(n_{t-1}\right)$, such that $n_{t}>0$ for all $t$. Since satisfaction of the Euler equation, $\bar{v}=0$, is a necessary condition for an interior solution to the household problem, it follows that there is no interior equilibrium with $n_{0}<\bar{n}^{2}$. Second, a sequence of employments, $n_{t}, t=0,1, \ldots$, which has the property $n_{t}=f\left(n_{t-1}\right)$ and $n_{0}>\bar{n}^{2}$, has the property $n_{t} \rightarrow 1$ as $t \rightarrow \infty$. Appealing again to the necessity of the Euler equation, we conclude that there is no interior equilibrium with $n_{0}>\bar{n}^{2}$. Third, $n_{t}=\bar{n}^{2}$ for all $t$ satisfies the Euler and transversality conditions and so corresponds to an interior equilibrium. Thus, the only deterministic interior equilibrium is 
the one that corresponds to $n_{t}=\bar{n}^{2}$ for $t=0,1, \ldots$ That sunspot equilibria are also ruled out follows from the fact that the Euler equation cuts the 45-degree line from below and from the arguments in Woodford (1986a). These remarks establish

Proposition 6.1. For the baseline parameterization and under the tax policy in (6.1), there is a unique interior equilibrium with $n_{t}=\bar{n}^{2}$ for all $t$.

Note that under the tax rate policy considered here, $\tau_{t}=0$ in equilibrium. Evidently, the mere threat to change tax rates is enough to rule out other equilibria. This feature of fiscal (and monetary) policies designed to select certain equilibria is common in models with multiple expectational equilibria. (See, for example, Boldrin 1992, p. 215 and Guesnerie and Woodford 1992, p. 380-382.)

\subsection{Optimal Allocations}

The efficient allocations correspond to a fictitious planner's choice of investment, employment, and consumption to maximize discounted utility subject to the resource constraint. We reproduce the utility function here for convenience:

$$
\sum_{t=0}^{\infty} \sum_{s^{t}} \beta^{t} \mu\left(s^{t}\right)\left\{\log \left[c\left(s^{t}\right)\right]+\sigma \log \left[1-n\left(s^{t}\right)\right]\right\}
$$

The resource constraint is

$$
c\left(s^{t}\right)+k\left(s^{t}\right)-(1-\delta) k\left(s^{t-1}\right) \leq k\left(s^{t-1}\right)\left[n\left(s^{t}\right)\right]^{2}, \text { for all } t, s^{t} .
$$


This problem simplifies greatly. Thus, using the change of variable in (3.2) and the identity

$$
\begin{aligned}
& \sum_{t=0}^{\infty} \sum_{s^{t}} \beta^{t} \mu\left(s^{t}\right) \log k\left(s^{t-1}\right) \\
= & \frac{1}{1-\beta}\left\{\log k_{0}+\beta \sum_{t=0}^{\infty} \sum_{s^{t}} \mu\left(s^{t}\right) \beta^{t} \log \lambda\left(s^{t}\right)\right\}
\end{aligned}
$$

the objective function can be written

$$
\begin{aligned}
& \sum_{t=0}^{\infty} \sum_{s^{t}} \beta^{t} \mu\left(s^{t}\right)\left\{\log \left[n\left(s^{t}\right)^{2}+1-\delta-\lambda\left(s^{t}\right)\right]+\frac{\beta}{1-\beta} \log \lambda\left(s^{t}\right)\right. \\
& \left.+\sigma \log \left[1-n\left(s^{t}\right)\right]\right\}+\frac{1}{1-\beta} \log k_{0} .
\end{aligned}
$$

In (6.5), consumption has been substituted out using the (scaled) resource constraint after replacing the weak inequality in (6.3) by a strict equality. Notice that the objective in (6.5) is separable across dates and states. This has two implications. First, unsurprisingly, the efficient allocations are insensitive to sunspots. Second, the efficient levels of employment and capital accumulation do not exhibit cycles. It is trivially verified that this result is independent of the curvature on leisure in the utility function, the degree of nonconvexity on labor in the production function, and the degree of homogeneity on capital in the resource constraint. ${ }^{24}$ Thus, for example, increasing the gains from bunching production, by raising the power on labor above 2 , and reducing the associated costs, by making utility linear in leisure, still does not imply that the efficient allocations exhibit cycles.

\footnotetext{
${ }^{24}$ Lack of cycling in the efficient allocations also obtains for utility functions which are homogeneous of degree $\gamma \neq 0$ in consumption. See the Appendix for further discussion.
} 
With our specification of preferences, optimizing (6.5) requires that the planner maximize, for each $t, s^{t}$,

$$
\log \left[n^{2}+1-\delta-\lambda\right]+\frac{\beta}{1-\beta} \log \lambda+\sigma \log [1-n]
$$

by choice of $n$ and $\lambda$, subject to

$$
0 \leq \lambda \leq n^{2}+1-\delta, 0 \leq n \leq 1
$$

The objective, (6.6), is not concave, because of the nonconcavity in the production function. However, for fixed $n,(6.6)$ is strictly concave in $\lambda$, and its optimal value is readily determined to be $\lambda=\beta\left(n^{2}+1-\delta\right)$. Substituting this into (6.6), the criterion maximized by the efficient allocations becomes

$$
\frac{1}{1-\beta} \log \left(n^{2}+1-\delta\right)+\sigma \log (1-n)
$$

after constant terms are ignored. The constraint on this problem is $0 \leq n \leq 1$. There are two values of $n$ that set the first-order condition associated with maximizing (6.8), and the larger of the two is the global optimum. This is given by $n^{0}$, where

$$
n^{0}=\frac{1}{2}\left[\phi+\sqrt{\phi^{2}-4 b}\right], \phi=\frac{2}{2+\sigma(1-\beta)}, b=\frac{\sigma(1-\beta)(1-\delta)}{2+\sigma(1-\beta)} .
$$

With the baseline parameter values, $n^{0}=0.98$, which implies that the optimal value of $\lambda$ is 1.94 , or 94 percent per quarter. The fact that equilibrium employment is so high reflects the 
fact that the efficient allocations internalize the externality in the production function.

It is easily verified that the tax rate which supports $n^{0}$ as an equilibrium is $\tau=-2$. It is not surprising that this involves a subsidy, since the tax must in effect coax individuals into internalizing the positive externality associated with production. Consider first the case in which the tax rate is simply fixed at $\tau=-2$ for every $n$. Let $\bar{v}\left(n, n^{\prime}\right)$ denote (3.6) after substituting out for $\tau=-2$. In effect, reducing $\tau$ from zero to -2 pushes the saddle in Figure 1a down, so that the $\omega=0$ plane now covers the seat of the saddle. The consequences can be seen in Figure 12a, which displays the values of $n^{\prime}$ that solve $\tilde{v}\left(n, n^{\prime}\right)=0$ for $n \in(0,1)$. Note the region of values for $n$ for which there are no values of $n^{\prime}$ that solve $\tilde{v}\left(n, n^{\prime}\right)=0$. In the other regions, there are generally two values of $n^{\prime}$ that solve this equation for each $n$. Interestingly, the unique intersection of these points with the 45 -degree line, at $n^{0}$, is associated with a slope greater than one. As a result, the equilibrium associated with $n^{0}, n^{0}, n^{0}, \ldots$ is determinate. However, there is at least one other equilibrium, $\tilde{n}, n^{0}, n^{0}, \ldots$ (See Figure 12a for $\tilde{n}$.) Evidently, the constant tax rate policy does not guarantee a unique equilibrium.

One way to construct a tax regime that selects only the desirable equilibrium follows the strategy taken in the previous subsection. Thus, consider

$$
\tau(n)=1-\frac{3 n^{0}}{n}
$$

Evidently, with this policy, $\tau\left(n^{0}\right)=-2$, so that there is an equilibrium associated with this tax policy which supports the efficient allocations. Also, it is easily verified that-following 
the same reasoning as in the preceding subsection-the Euler equation has only one branch. In addition, we found for the baseline parameter values that this branch is monotone, and it cuts the 45-degree line from below. It follows by the logic leading to Proposition 6.1 that there is a unique interior equilibrium.

\section{Conclusion and Directions for Future Research}

We have displayed a model environment which rationalizes implementing a tax regime which is procyclical in the sense that if aggregate employment were to rise, the government stands committed to raise the tax rate. In this sense, the environment seems to rationalize the importance assigned by macroeconomists before the 1970s to devising automatic stabilizer tax systems. ${ }^{25}$ But, since a properly constructed tax regime eliminates fluctuating equilibria, the actual tax rate is constant. We expect this basic result to survive in versions of our model with fundamental shocks. Thus, if there were technology shocks, we conjecture that the optimal tax rate regime would move procyclically with sunspot shocks, but would not vary with technology shocks. Assuming an efficient tax regime eliminates sunspot equilibria, the optimal "automatic stabilizer" tax rate would then not be procyclical in equilibrium. An interesting question for future research would be to investigate what happens when the tax regime cannot respond differently to fluctuations due to sunspots and to fluctuations due to technology shocks. Possibly, under these circumstances an efficiently constructed tax regime would exhibit procyclical behavior in equilibrium. Another interesting question for

\footnotetext{
${ }^{25}$ For a discussion of "automatic stabilizers," see Christiano (1984).
} 
future research would explore the robustness of our result that a properly constructed tax regime necessarily stabilizes fluctuations. We have shown that this is so under a particular homogeneity assumption on the resource constraint. But, standard models do not satisfy this condition. 


\begin{tabular}{|r|r|r|r|r|r|}
\hline \multicolumn{7}{|c|}{ Table 1: First-Moment Properties } \\
\hline$n$ & $c / y$ & $k / y$ & $i / y$ & growth in $k$ & growth in $y$ \\
\hline \multicolumn{6}{|c|}{ Panel A: U.S. Data } \\
\hline 0.23 & 0.73 & 10.62 & 0.27 & 1.0047 & 1.0040 \\
\hline \multicolumn{7}{|c|}{ Panel C: Real Business Cycle Model } \\
\hline 0.23 & 0.73 & 10.64 & 0.27 & 1.0040 & 1.0040 \\
\hline \multicolumn{7}{|c|}{ Panel B: Conventional Sunspot } \\
\hline 0.309 & 0.745 & 10.46 & 0.255 & 1.0045 & 1.0046 \\
\hline \multicolumn{7}{|c|}{ Panel D: Regime Switching Sunspot } \\
\hline 0.094 & 5.17 & 298 & -4.17 & 0.989 & 4.74 \\
\hline
\end{tabular}

Note: Entries in the table are the mean of the indicated variable. U.S. data results are taken from Christiano (1988). Statistics based on model economies are computed using 100 artificial data sets of length 114 each. Entries in the table are an average of 100. 


\begin{tabular}{|r|r|r|r|r|r|r|}
\hline \multicolumn{7}{|c|}{ Table 2: Second-Moment Properties } \\
\hline$x_{t}$ & $\sigma_{x} / \sigma_{y}$ & \multicolumn{5}{|c|}{ Correlation of $y_{t}$ with $x_{t+\tau}$} \\
\hline & & $\tau=2$ & $\tau=1$ & $\tau=0$ & $\tau=-1$ & $\tau=-2$ \\
\hline \multicolumn{7}{|c|}{ Panel A: U.S. Data } \\
\hline$y$ & 0.02 & 0.65 & 0.86 & 1.00 & 0.86 & 0.65 \\
\hline$c$ & 0.46 & 0.48 & 0.66 & 0.78 & 0.76 & 0.61 \\
\hline$i$ & 2.91 & 0.33 & 0.56 & 0.71 & 0.68 & 0.57 \\
\hline$n$ & 0.82 & 0.69 & 0.81 & 0.82 & 0.66 & 0.41 \\
\hline$y / n$ & 0.58 & 0.12 & 0.32 & 0.55 & 0.55 & 0.53 \\
\hline$y / n, n$ & 0.70 & -0.17 & -0.07 & -0.03 & 0.21 & 0.33 \\
\hline \multicolumn{7}{|r|}{ Panel B: Standard Real Business Cycle } \\
\hline$y$ & 0.02 & 0.51 & 0.74 & 1.00 & 0.74 & 0.51 \\
\hline$c$ & 0.55 & 0.59 & 0.78 & 0.98 & 0.69 & 0.44 \\
\hline$i$ & 2.37 & 0.45 & 0.70 & 0.99 & 0.76 & 0.55 \\
\hline$n$ & 0.38 & 0.40 & 0.67 & 0.98 & 0.77 & 0.57 \\
\hline$y / n$ & 0.63 & 0.57 & 0.78 & 0.99 & 0.71 & 0.47 \\
\hline$y / n, n$ & 1.65 & 0.61 & 0.77 & 0.94 & 0.61 & 0.33 \\
\hline & & & & 0.51 \\
\hline
\end{tabular}

Note: Results are taken from Christiano and Todd (1996, tables 2 and 3). Panel B results are based on 2,000 artificial observations simulated from a standard real business cycle model. In both panels, prior to computing statistics, data were logged and HodrickPrescott filtered. The model corresponds to the one in this paper, with $\sigma=3.92$, $\gamma=0, \delta=0.021, \alpha=0.344$, and a production function has the form $Y=K^{\alpha}(z n)^{(1-\alpha)}$, with $z=z_{-1} \exp (\lambda)$, and $\lambda \sim \operatorname{IIN}\left(0.004,0.018^{2}\right)$. The last two rows of each panel report the standard deviation of productivity $(y / n)$ relative to that of hours $(n)$. The correlations reported there are $\operatorname{corr}\left[(y / n)_{t}, n_{t-\tau}\right]$. 


\begin{tabular}{|c|c|c|c|c|c|c|}
\hline \multirow[t]{2}{*}{$x_{t}$} & \multirow[t]{2}{*}{$\sigma_{x} / \sigma_{y}$} & \multicolumn{5}{|c|}{ Correlation of $y_{t}$ with $x_{t+\tau}$} \\
\hline & & $\tau=2$ & $\tau=1$ & $\tau=0$ & $\tau=-1$ & $\tau=-2$ \\
\hline \multicolumn{7}{|c|}{ Panel A: Conventional Sunspot } \\
\hline$y$ & 0.02 & 0.35 & 0.63 & 1.00 & 0.63 & 0.35 \\
\hline$c$ & 0.33 & 0.58 & 0.72 & 0.87 & 0.44 & 0.13 \\
\hline$i$ & 3.13 & 0.26 & 0.57 & 0.99 & 0.66 & 0.40 \\
\hline$n$ & 0.51 & 0.22 & 0.54 & 0.98 & 0.66 & 0.42 \\
\hline$y / n$ & 0.52 & 0.46 & 0.69 & 0.98 & 0.57 & 0.27 \\
\hline$y / n, n$ & 1.02 & 0.49 & 0.68 & 0.91 & 0.44 & 0.11 \\
\hline \multicolumn{7}{|c|}{ Panel B: Regime Switching Sunspot } \\
\hline$y$ & 0.78 & -0.07 & -0.07 & 1.00 & -0.07 & -0.07 \\
\hline$c$ & 0.06 & 0.25 & 0.30 & 0.35 & -0.42 & -0.35 \\
\hline$i$ & na & na & na & na & na & na \\
\hline$n$ & 0.54 & -0.11 & 0.11 & 0.99 & -0.01 & -0.03 \\
\hline$y / n$ & 0.47 & -0.03 & -0.02 & 0.99 & -0.13 & -0.12 \\
\hline$y / n, n$ & 0.88 & 0.01 & 0.02 & 0.96 & -0.19 & -0.17 \\
\hline
\end{tabular}

Note: Model statistics are computed in the same way as for Panel B in Table 2. The notation "na" appears in the investment column of Panel B, because gross investment is often negative. 
Table 4: Percentage Utility Gain Relative to Constant Equilibrium

\begin{tabular}{|c|c|c|}
\hline Conventional Sunspot I & Conventional Sunspot II & Regime Switching \\
\hline $0.9 \%$ & $11.2 \%$ & $-289 \%$ \\
\hline
\end{tabular}

Note: This is the constant percentage decrease in consumption required for households in the indicated equilibrium to be indifferent between that equilibrium and the constant equilibrium at $n=\bar{n}^{2}$. Let $v$ denote the discounted utility associated with the constant employment level. Let $\bar{v}$ denote the discounted utility associated with one of the other equilibria. Then, the number in the table is $100[\exp ((1-\beta)(\tilde{v}-v))-1]$. 


\section{A. Appendix: Linearity of Policy Rules Under Homogeneity}

In this appendix, we establish efficiency for a policy of the form, $k_{t+1}=\lambda^{*} k_{t}$ and $n_{t}=n^{*}$, where $\lambda^{*}, n^{*}$ are fixed numbers. We do this for a class of economies in which the resource constraint is homogeneous in capital and in which preferences are homogeneous in consumption. Our result parallels that in Alvarez and Stokey (1995), except their environment does not explicitly allow for variable hours worked.

Consider the following planning problem:

$$
\max _{\left\{k_{t+1}, n_{t}, c_{t}\right\}} \sum_{t=0}^{\infty} \beta^{t} u\left(c_{t}, n_{t}\right), 0<\beta<1
$$

subject to the following feasibility constraints:

$$
k_{0}>0 \text { is given, } 0 \leq c_{t} \leq F\left(k_{t}, k_{t+1}, n_{t}\right), 0 \leq n_{t} \leq 1, k_{t+1} \geq 0 \text {, for } t=0,1,2, \ldots
$$

We assume that $F$ is homogeneous:

$$
F\left(k, k^{\prime}, n\right)=k^{\psi} f\left(\frac{k^{\prime}}{k}, n\right), \text { where } f(\lambda, n) \equiv F(1, \lambda, n), \lambda=\frac{k^{\prime}}{k}, \psi \geq 0
$$

In terms of $\lambda$ and $n$, the constraints on the planner are:

$$
B \equiv\{\lambda, n: 0 \leq n \leq 1,0 \leq \lambda, \text { and } f(\lambda, n) \geq 0\}
$$

That is, the planner's feasible set is the set of infinite sequences, $\left\{\lambda_{t}, n_{t}\right\}_{t=0}^{\infty}$, such that $\lambda_{t}, n_{t} \in B$ for each $t \geq 0$. We place the following assumptions on $f$ :

$$
f: B \rightarrow R \text {, continuous, decreasing in } \lambda \text {, and increasing in } n \text {. }
$$

Also,

there exists a largest value of $\lambda, \bar{\lambda}>0$, such that $f(\bar{\lambda}, 1) \geq 0$

$$
\beta(\bar{\lambda})^{\psi \gamma}<1
$$


and

$$
\text { there exists } 0 \leq \tilde{n} \leq 1 \text { such that } f(1, \tilde{n})>0 \text {. }
$$

We place the following assumptions on $u$ :

$$
u(c, n)=c^{\gamma} g(n) / \gamma, \gamma \neq 0, g(n) \geq 0, g \text { is continuous and decreasing. }
$$

We have the following proposition:

\section{Proposition A.1. If}

(i) the functions $F$ and $u$ satisfy (A.2)-(A.3), and (A.6),

(ii) (A.4) holds when $\gamma>0$, and (A.5) holds when $\gamma<0$.

then, a policy of the following form solves (A.1):

$$
k_{t+1}=\lambda^{*} k_{t}, n_{t}=n^{*}, t \geq 0, \text { for fixed }\left(n^{*}, \lambda^{*}\right) \in B
$$

Proof. Write $u(c, n)=k^{\gamma \psi}(f(\lambda, n))^{\gamma} g(n) / \gamma$. Also,

$$
k_{t}^{\gamma \psi}=\left(\prod_{j=0}^{t-1} \lambda_{j}^{\gamma \psi}\right) k_{0}^{\gamma \psi}, t=1,2, \ldots
$$

Simple substitution establishes

$$
v\left(k_{0}\right)=\max _{\left\{k_{t+1}, n_{t}\right\}_{t=0}^{\infty}} \sum_{t=0}^{\infty} \beta^{t} u\left(F\left(k_{t}, k_{t+1}, n_{t}\right), n_{t}\right)=k_{0}^{\gamma \psi} w
$$

where:

$$
w=\max _{\left\{\left(\lambda_{t}, n_{t}\right) \in B\right\}_{t=0}^{\infty}} \sum_{t=0}^{\infty} \beta^{t}\left(\prod_{j=0}^{t-1} \lambda_{j}^{\gamma \psi}\right) \frac{\left(f\left(\lambda_{t}, n_{t}\right)\right)^{\gamma} g\left(n_{t}\right)}{\gamma} .
$$

We establish $-\infty<w<\infty$. When $\gamma<0$, then $u$ is bounded above by zero and so trivially, $w<\infty$. For the case $\gamma>0$, consider the (infeasible!) policy of applying the entire time endowment both to labor effort and to leisure, and of applying all of output both to consumption and to investment. The value of this policy is $\bar{w}=(f(0,1))^{\gamma} g(0) /\left[\gamma\left(1-\beta \bar{\lambda}^{\gamma \psi}\right)\right]$. We have $w<\infty$, since $w \leq \bar{w}<\infty$. To establish $-\infty<w$ when $\gamma>0$ note simply that 
$u$ is bounded below by zero in this case. For the case $\gamma<0$, note that the feasible policy, $\lambda_{t}=1, n_{t}=\tilde{n}$, for $t \geq 0$ has return $k_{0}^{\gamma \psi} \tilde{w}$, where $\tilde{w}=f(1, \tilde{n})^{\gamma} g(\bar{n}) /[\gamma(1-\beta)]$, so that $-\infty<\tilde{w} \leq w$.

We have established that $w$ is a finite scalar. By writing (A.7) out explicitly, one verifies that $w$ satisfies the following expression:

$$
w=\max _{\left(\lambda_{0}, n_{0}\right) \in B}\left\{\left(f\left(\lambda_{0}, n_{0}\right)\right)^{\gamma} g\left(n_{0}\right) / \gamma+\beta\left(\lambda_{0}\right)^{\gamma \psi} w\right\} .
$$

Let $\lambda^{*}$ and $n^{*}$ denote values of $\lambda_{0}$ and $n_{0}$ that solve the above maximization problem. The result follows from the fact that these solve a problem in which the objectives and constraints are independent of $k_{0}$. Q.E.D.

Remark 1. The proof for the class of utility functions $u(c, n)=\log (c)+g(n)$ is a trivial perturbation on the argument in the text.

Remark 2. When $\gamma>0$, then the fixed point problem in (A.8) can be shown to be the fixed point of a contraction mapping. In this case, $w$ in (A.7) is the only solution to (A.8), and the contraction mapping theorem provides an iterative algorithm for computing $w, \lambda^{*}$, and $n^{*}$. When $\gamma<0$, the mapping implicitly defined in (A.8) is not necessarily a contraction. Alvarez and Stokey (1995) supply iterative schemes for computing $w$ in this case. 


\section{References}

[1] Altug, Sumru, 1989, "Time to Build and Aggregate Fluctuations: Some New Evidence," International Economic Review 30, pp. 889-920.

[2] Alvarez, Fernando, and Nancy L. Stokey, 1995, "Dynamic Programming with Homogeneous Functions," manuscript, University of Chicago.

[3] Azariadis, Costas, 1981, "Self-Fulfilling Prophesies," Journal of Economic Theory 25, pp. 380-396.

[4] Baxter, Marianne, and Robert King, 1991, "Productive Externalities and Business Cycles," Discussion Paper 53, Institute for Empirical Macroeconomics, Federal Reserve Bank of Minneapolis, November.

[5] Beaudry, Paul, and Michael B. Devereux, 1994, "Monopolistic Competition, Price Setting and the Effects of Real and Monetary Shocks," manuscript, University of British Columbia.

[6] Benhabib, Jess, and Roger E. A. Farmer, 1994, "Indeterminacy and Growth," Journal of Economic Theory 63, pp. 19-41.

[7] Benhabib, Jess, and Roger E. A. Farmer, 1995, "Indeterminacy and Sector-Specific Externalities," manuscript, department of economics, UCLA, May.

[8] Benhabib, Jess, and Roger E. A. Farmer, 1996, "The Monetary Transmission Mechanism," manuscript.

[9] Benhabib, Jess, and Roberto Perli, 1994, "Uniqueness and Indeterminacy: On the Dynamics of Endogenous Growth," Journal of Economic Theory 63, pp. 113-142.

[10] Benhabib, Jess, and Aldo Rustichini, 1994, "Introduction to the Symposium on Growth, Fluctuations, and Sunspots: Confronting the Data," Journal of Economic Theory 63, pp. 1-18.

[11] Boldrin, Michele, 1992, "Dynamic Externalities, Multiple Equilibria, and Growth," Journal of Economic Theory 58, no. 2, December.

[12] Boldrin, Michele, Nobuhiro Kiyotaki, and Randall Wright, 1993, "A Dynamic Equilibrium Model of Search, Production and Exchange," Journal of Economic Dynamics and Control.

[13] Boldrin, Michele, and Aldo Rustichini, 1994, "Growth and Indeterminacy in Dynamic Models with Externalities," Econometrica 62, no. 2.

[14] Boldrin, Michele, and Michael Woodford, 1990, "Equilibrium Models Displaying Endogenous Fluctuations and Chaos," Journal of Monetary Economics 25, pp. 189-222. 
[15] Bryant, John, 1981, "Bank Collapse and Depression," Journal of Money, Credit and Banking 13, pp. 454-464.

[16] Bryant, John, 1983, "A Simple Rational Expectations Keynes-Type Model," Quarterly Journal of Economics 98, no. 3.

[17] Burnside, Craig, and Martin Eichenbaum, 1995, "Factor Hoarding and the Propagation of Business Cycle Shocks," Working Paper 4675, National Bureau of Economic Research.

[18] Burnside, Craig, Martin Eichenbaum, and Sergio Rebelo, 1995, "Capacity Utilization and Returns to Scale," in Ben Bernanke and Julio Rotemberg, editors, Macroeconomics Annual.

[19] Cass, David, and Karl Shell, 1983, "Do Sunspots Matter?" Journal of Political Economy 91, pp. 193-227.

[20] Christiano, Lawrence J., 1984, "A Reexamination of the Theory of Automatic Stabilizers," Carnegie-Rochester Conference Series on Public Policy 20.

[21] Christiano, Lawrence J., 1988, "Why Does Inventory Investment Fluctuate So Much?" Journal of Monetary Economics.

[22] Christiano, Lawrence J., and Martin Eichenbaum, 1992, "Current Real-business-cycle Theories and Aggregate Labor Market Fluctuations," American Economic Review 82, pp. $430-450$.

[23] Christiano, Lawrence J., and Richard Todd, 1996, "Time to Plan and Aggregate Fluctuations," Federal Reserve Bank of Minneapolis Quarterly Review 20, pp. 14-27.

[24] Cochrane, John, 1995, "Shocks," Carnegie-Rochester Conference on Public Policy.

[25] Cogley, Timothy, and James Nason, 1995, "Output Dynamics in Real-Business-Cycle Models," American Economic Review 3, pp. 492-511.

[26] Cole, Harold L., and Timothy Kehoe, 1996, "Self-Fulfilling Debt Crises," Research Department Staff Report 210, Federal Reserve Bank of Minneapolis.

[27] Cooper, Russell, and Andrew John, 1988, "Coordinating Coordination Failures in Keynesian Models," Quarterly Journal of Economics 103, August, pp. 441-463.

[28] Dagsvik, John, and Boyan Jovanovic, 1994, "Was the Great Depression a Low-Level Equilibrium," European Economic Review, December.

[29] Devaney, Robert L., 1989, An Introduction to Chaotic Dynamical Systems, second edition, Addison-Wesley: Redwood City, California.

[30] Diamond, Douglas, and Philip Dybvig, 1983, "Bank Runs, Deposit Insurance, and Liquidity," Journal of Political Economy 91, no. 3, pp. 401-419. 
[31] Diamond, Peter, 1982, "Aggregate-Demand Management in Search Equilibrium," Journal of Political Economy 90, no. 5, pp. 881-894.

[32] Domowitz, Ian, and Mahmoud A. El-Gamal, 1993, "A Consistent Test of Stationary Ergodicity," Econometric Theory 9, 589-601.

[33] Domowitz, Ian, and Mahmoud A. El-Gamal, 1994, "Is Your Model Chaotic? A Consistent Simulation-Based Test," in V. Lakshmikantham and W. de Gruyten, editors, Proceedings of the First World Congress of Nonlinear Analysis, Walter de Gruyter Publishing Company.

[34] El-Gamal, Mahmoud, 1991, "Non-Parametric Estimation of Deterministically Chaotic Systems," Economic Theory 1, pp. 147-167.

[35] Farmer, Roger E. A., and Guo, J.-T., 1994, "Real Business Cycles and the Animal Spirits Hypothesis," Journal of Economic Theory 63, pp. 42-73.

[36] Farmer, Roger E. A., and Guo, J.-T., 1995, "The Econometrics of Indeterminacy: An Applied Study," Journal of Monetary Economics.

[37] Farmer, Roger E. A., and Michael Woodford, 1984, "Self-Fulfilling Prophecies and the Business Cycle," Center for Analytic Research in Economics and Social Science, Working Paper 84-12, University of Pennsylvania, April.

[38] Fischer, Stanley, 1980, "On Activist Monetary Policy with Rational Expectations," in Stanley Fischer, editor, Rational Expectations and Economic Policy, University of Chicago Press.

[39] Gali, Jordi, 1994a, "Monopolistic Competition, Business Cycles, and the Composition of Aggregate Demand," Journal of Economic Theory 63, pp. 73-96.

[40] Gali, Jordi, 1994b, "Monopolistic Competition, Endogenous Markups and Growth," European Economic Review 38, pp. 748-756.

[41] Grandmont, Jean-Michel, 1986, "Stabilizing Competitive Business Cycles," in JeanMichel Grandmont, editor, Nonlinear Economic Dynamics, Academic Press.

[42] Guesnerie, Roger, and Michael Woodford, 1992, "Endogenous Fluctuations," in JeanJacques Laffont, editor, Advances in Economic Theory, Sixth World Congress, vol. 2, Cambridge University Press.

[43] Guo, Jang-Ting, and Kevin Lansing, 1996, "State-Contingent Fiscal Policy and Sunspot Equilibria," unpublished manuscript, University of California, Riverside.

[44] Hall, George, 1996, "Overtime, Effort and the Propagation of Business Cycle Shocks," Journal of Monetary Economics, forthcoming. 
[45] Hamilton, James, 1989, "A New Approach to the Economic Analysis of Nonstationary Time Series and the Business Cycle," Econometrica 57, pp. 331-339.

[46] Hamilton, James, 1994, Time Series Analysis, Princeton University Press: Princeton, New Jersey.

[47] Hansen, Lars Peter, 1982, "Large Sample Properties of Generalized Method of Moment Models," Econometrica 50, 1269-1286.

[48] Hansen, Lars Peter, and Kenneth Singleton, 1982, "Generalized Instrumental Variables Estimation of Nonlinear Rational Expectations Models," Econometrica 50, pp. 1269 1288.

[49] Howitt, Peter, and Preston McAfee, 1988, "Stability of Equilibria with Externalities," Quarterly Journal of Economics 103, pp. 261-278.

[50] Imrohoroglu, Selahattin, 1993, "Testing for Sunspot Equilibria in the German Hyperinflation," Journal of Economic Dynamics and Control 17, 289-317.

[51] Jovanovic, Boyan, 1989, "Observable Implications of Models with Multiple Equilibria," Econometrica 57, no. 6, pp. 1431-1437.

[52] Klenow, Peter J., 1992, "Multiple Steady States and Business Cycles," manuscript, Graduate School of Business, University of Chicago.

[53] Krugman, Paul, 1991, "History Versus Expectations," Quarterly Joumal of Economics 106 , no. 2, pp. 651-667.

[54] Kydland, Finn, and Edward C. Prescott, 1980, "A Competitive Theory of Fluctuations and the Feasibility and Desirability of Stabilization Policy," in Stanley Fischer, editor, Rational Expectations and Economic Policy, University of Chicago Press.

[55] Lasota, Andrzej, and Michael C. Mackey, 1985, Probabilistic Properties of Deterministic Systems, Cambridge University Press.

[56] Matheny, Kenneth J., 1994, "Increasing Returns and Monetary Policy," manuscript, Purdue University.

[57] Matsuyama, Kiminori, 1991a, "Increasing Returns, Industrialization, and Indeterminacy of Equilibrium," Quarterly Journal of Economics 106, no. 2, pp. 617-650.

[58] Matsuyama, Kiminori, 1991b, "Endogenous Price Fluctuations in an Optimizing Model of a Monetary Economy," Econometrica 59, pp. 1617-1631.

[59] McGrattan, Ellen R., Richard Rogerson, and Randall Wright, 1996, "An Equilibrium Model of the Business Cycle With Household Production and Fiscal Policy," International Economic Review, forthcoming. 
[60] Mortensen, Dale T., 1989, "The Persistence and Indeterminacy of Unemployment in Search Equilibrium," Scandinavian Joumal of Economics 91, pp. 347-370.

[61] Mortensen, Dale T., 1991, "Equilibrium Unemployment Cycles," unpublished manuscript, Northwestern University.

[62] Poole, William, 1970, "Optimal Choice of Monetary Policy Instruments in a Simple Stochastic Macro Model," Quarterly Journal of Economics, May, pp. 197-216.

[63] Rebelo, Sergio, 1991, "Long-Run Policy Analysis and Long-Run Growth," Journal of Political Economy 99, no. 3, pp. 500-521.

[64] Romer, Paul, 1986, "Increasing Returns and Long-Run Growth," Journal of Political Economy 94, no. 5, pp. 1002-1037.

[65] Romer, Paul, 1987, "Growth Based on Increasing Returns Due to Specialization," American Economic Review Papers and Proceedings 77, no. 2, May.

[66] Rotemberg, Julio, and Michael Woodford, 1996, "Real Business Cycles and the Forecastable Movements in Output, Hours, and Consumption," American Economic Review 86 , pp. $71-89$.

[67] Sargent, Thomas, 1979, Macroeconomic Theory, Academic Press.

[68] Sargent, Thomas, and Neil Wallace, 1987, "Inflation And The Government Budget Constraint," in A. Razin and E. Sadka, editors, Economic Policy in Theory and Practice, MacMillan Press: New York.

[69] Schmitt-Grohe, Stephanie, 1995, "Comparing Four Models of Aggregate Fluctuations Due to Self-Fulfilling Expectations," Federal Reserve Board of Governors Finance and Economics Discussion Series 95-17, Washington, D.C.

[70] Schmitt-Grohe, Stephanie, and Martin Uribe, 1996, "Balanced-Budget Rules, Distortionary Taxes, and Aggregate Instability," unpublished manuscript, Federal Reserve Board of Governors, Washington, D.C.

[71] Stokey, Nancy, and Robert E. Lucas, with Edward Prescott, 1989, Recursive Methods in Economic Dynamics, Harvard University Press.

[72] Shleifer, Andrei, 1986, "Implementation Cycles," Journal of Political Economy 94, no. 6, pp. 1163-1190.

[73] Watson, Mark, 1993, "Measures of Fit for Calibrated Models," Journal of Political Economy 101, no. 6, pp. 1011-1041.

[74] Woodford, Michael, 1986a, "Stationary Sunspot Equilibria: The Case of Small Fluctuations Around a Deterministic Steady State," unpublished manuscript, University of Chicago, September. 
[75] Woodford, Michael, 1986b, "Stationary Sunspot Equilibria in a Finance Constrained Economy," Journal of Economic Theory 40, no. 1, October.

[76] Woodford, Michael, 1987, "Three Questions About Sunspot Equilibria as an Explanation of Economic Fluctuations," American Economic Review Papers and Proceedings 77, no. 2, May, pp. 93-98.

[77] Woodford, Michael, 1988, "Expectations, Finance, and Aggregate Instability," in M. Kohn and S-C. Tsiang, editors, Finance Constraints, Expectations, and Macroeconomics.

[78] Woodford, Michael, 1991, "Self-Fulfilling Expectations and Fluctuations in Aggregate Demand," in N. Gregory Mankiw and David Romer, editors, New Keynesian Economics, vol. 2, Coordination Failures and Real Rigidities, MIT Press.

[79] Woodford, Michael, 1994, "Determinancy of Equilibrium Under Alternative Policy Regimes," Economic Theory 4, no. 3, pp. 323-326. 


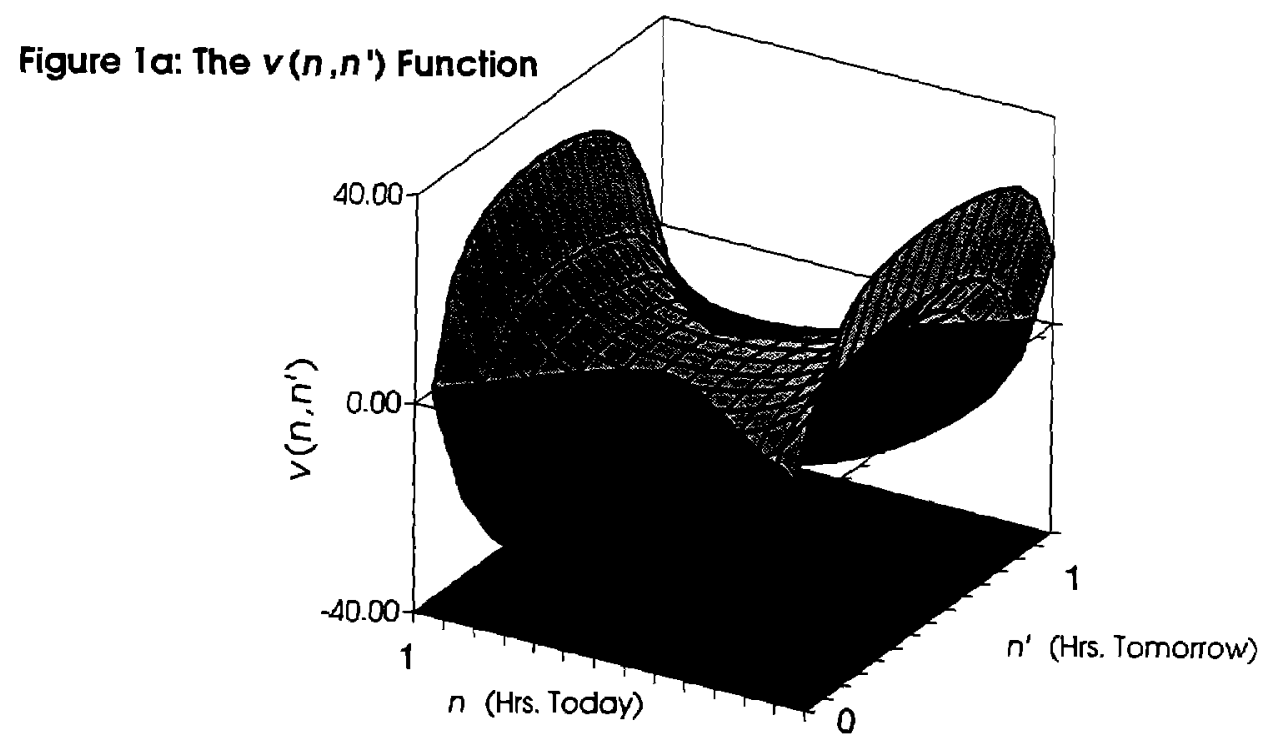

Figure 1b: Contour: $v\left(n, n^{\prime}\right)=0$

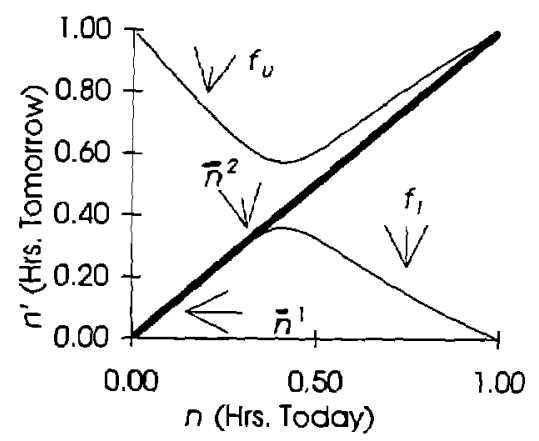

Figure 1c: Close-up of Figure ib

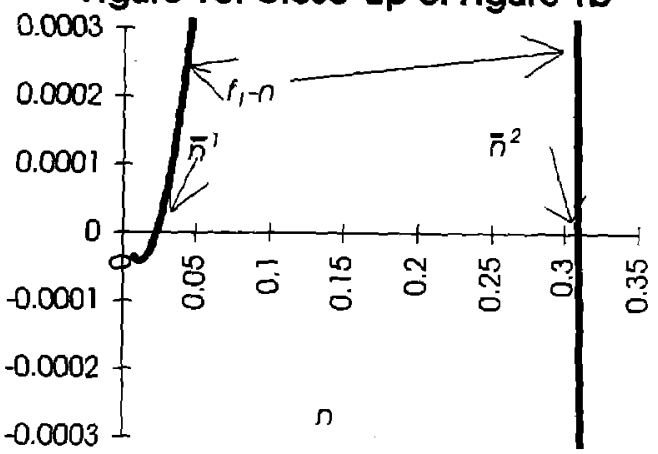

Note: Figure 1a is a three-dimensional view of the function $v$ in equation (3.6), computed using the standard parameter values. The dark and light regions identify the parts of $v$ that are less than and greater than zero, respectively. Figure $1 b$ shows the values of $n^{\prime}$ that $\operatorname{set} v(n, n)$ to zero, given $n$. Here, $f_{l}$ and $f_{u}$ denote the lower and upper branch functions defined in (3.9), respectively. Also, $\bar{n}^{\prime}$ and $\bar{n}^{2}$ denote the points where $f_{l}$ crosses the 45-degree line. Figure 1c displays $f_{i}(n)-n$ from Figure $1 \mathrm{~b}$ for values of $n$ in a neighborhood of the origin. It shows that $f_{l}$ first cuts the 45 -degree line from below, at $\bar{n}^{I}$, and then again from above, at $\bar{n}^{2}$. 
Figure 2: Two Equilibria on the Lower Branch Figure 3: Testing Sensitivity to Initial Conditions
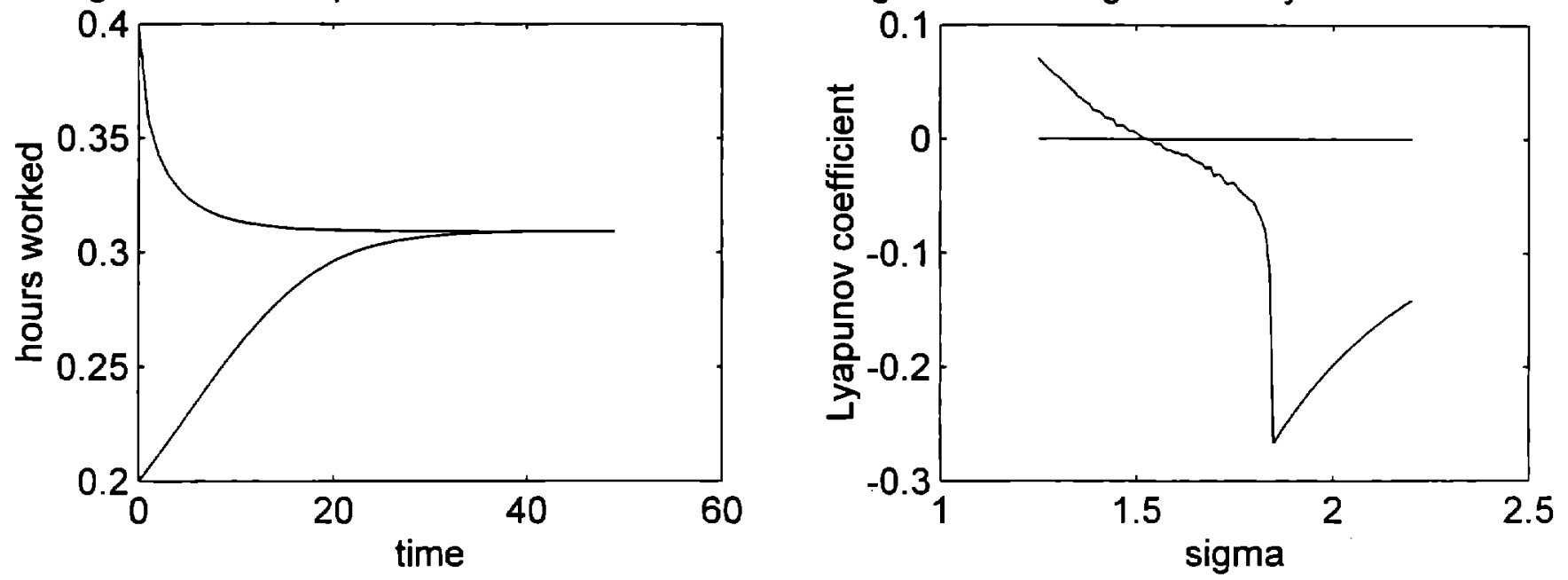

Figure 4a: Fraction of Available Time Worked

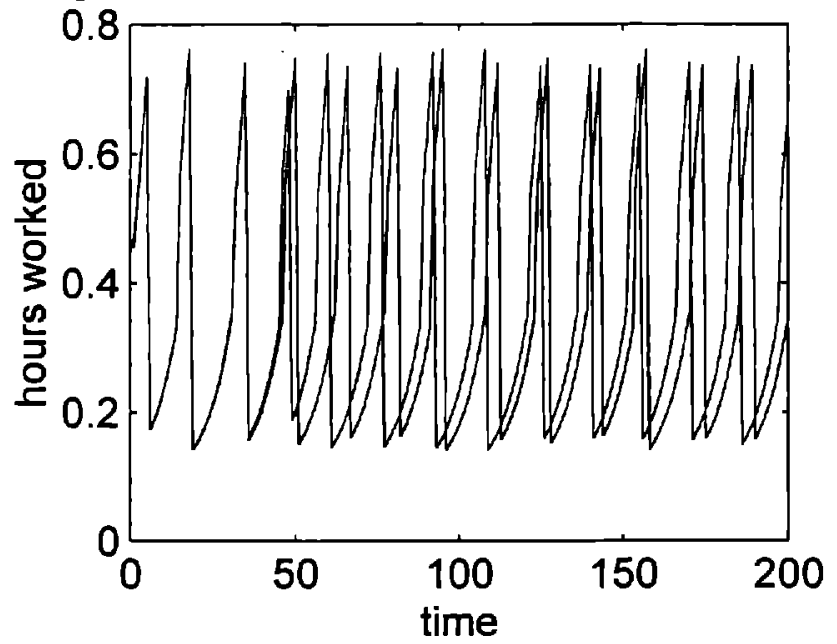

Figure 4b: Figure $4 a$, continued

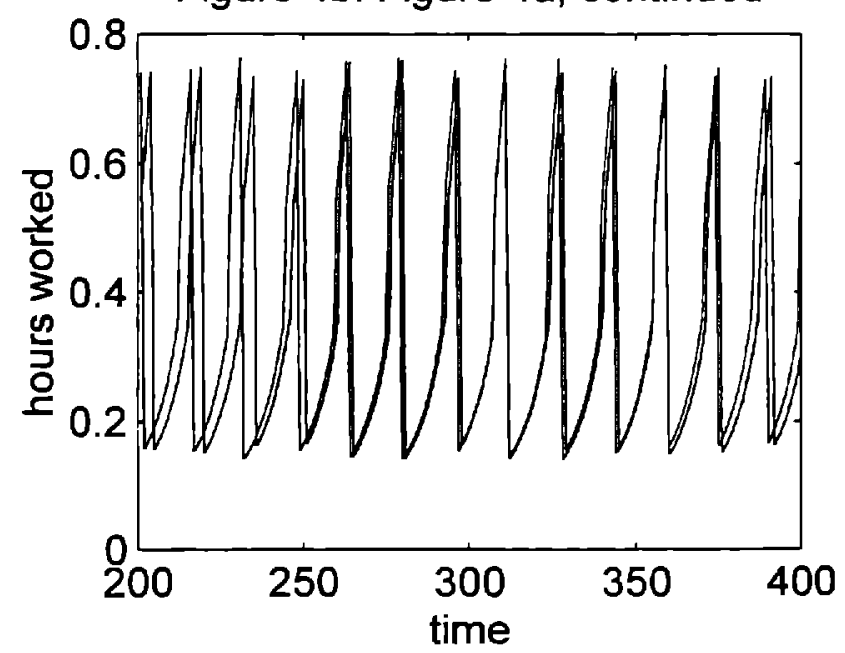


Figure 5: Histograms of Four Orbits
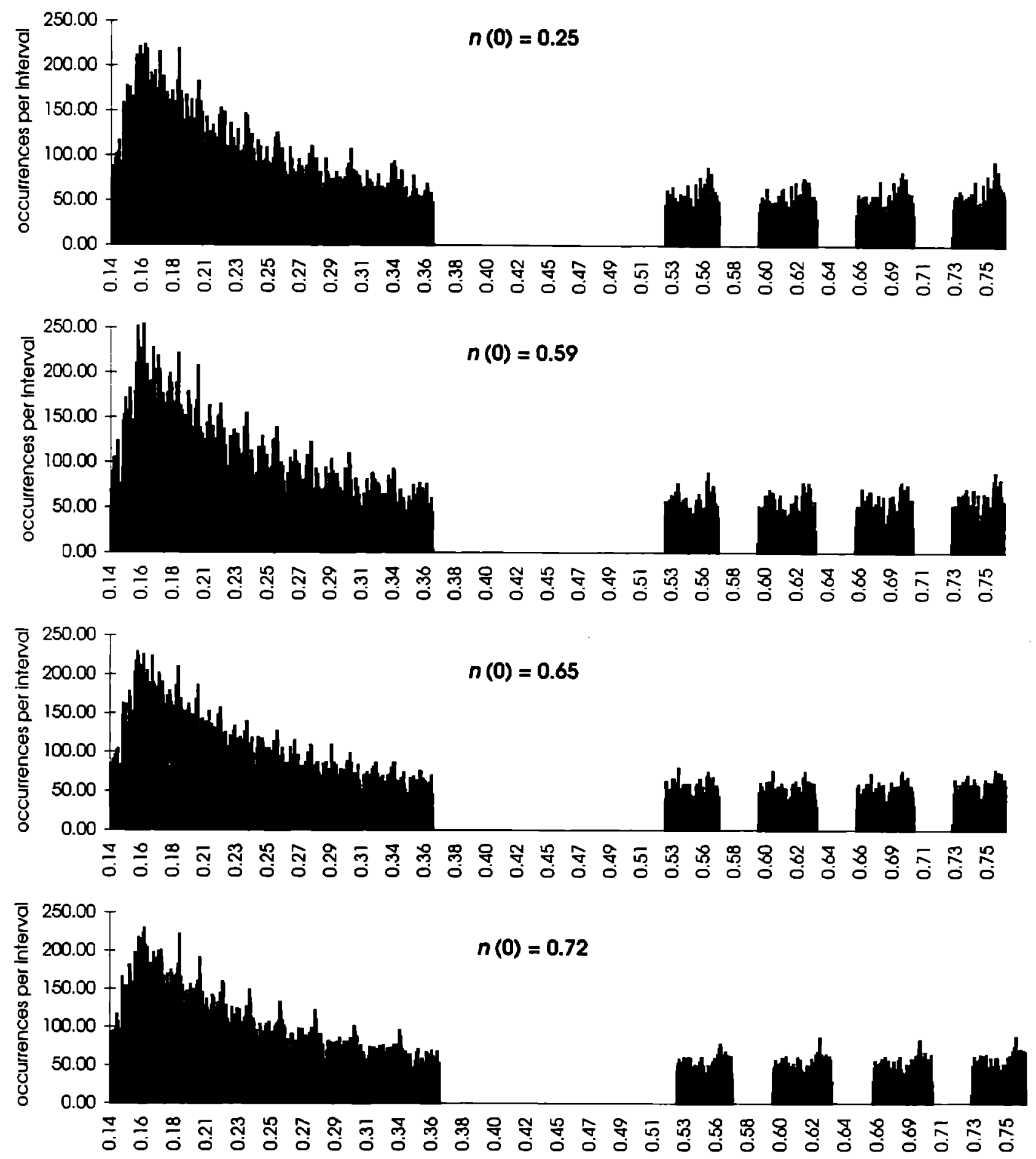

Note: Four histograms of 50,000 iterates on $f$, defined in (4.1), using standard parameter values, except $\sigma=1.25$. The iterates are differentiated according to the initial condition on $n$, as indicated. 
Figure 6: Density Functions Induced by $f$
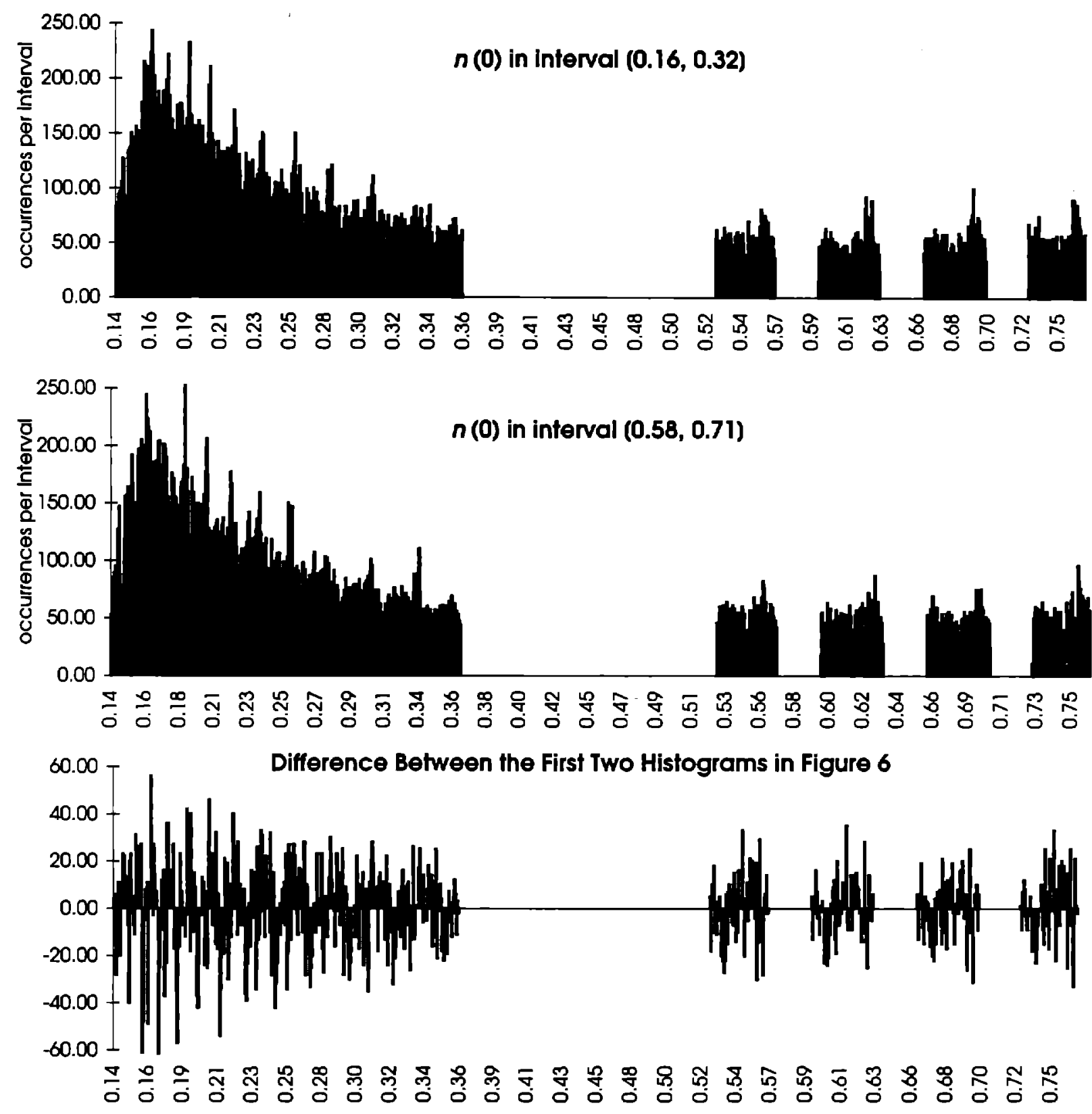

Note: The top two graphs show the density of iterate number 3,000 on the map $f$ defined in (4.1), with initial condition drawn uniformly from the indicated interval. 

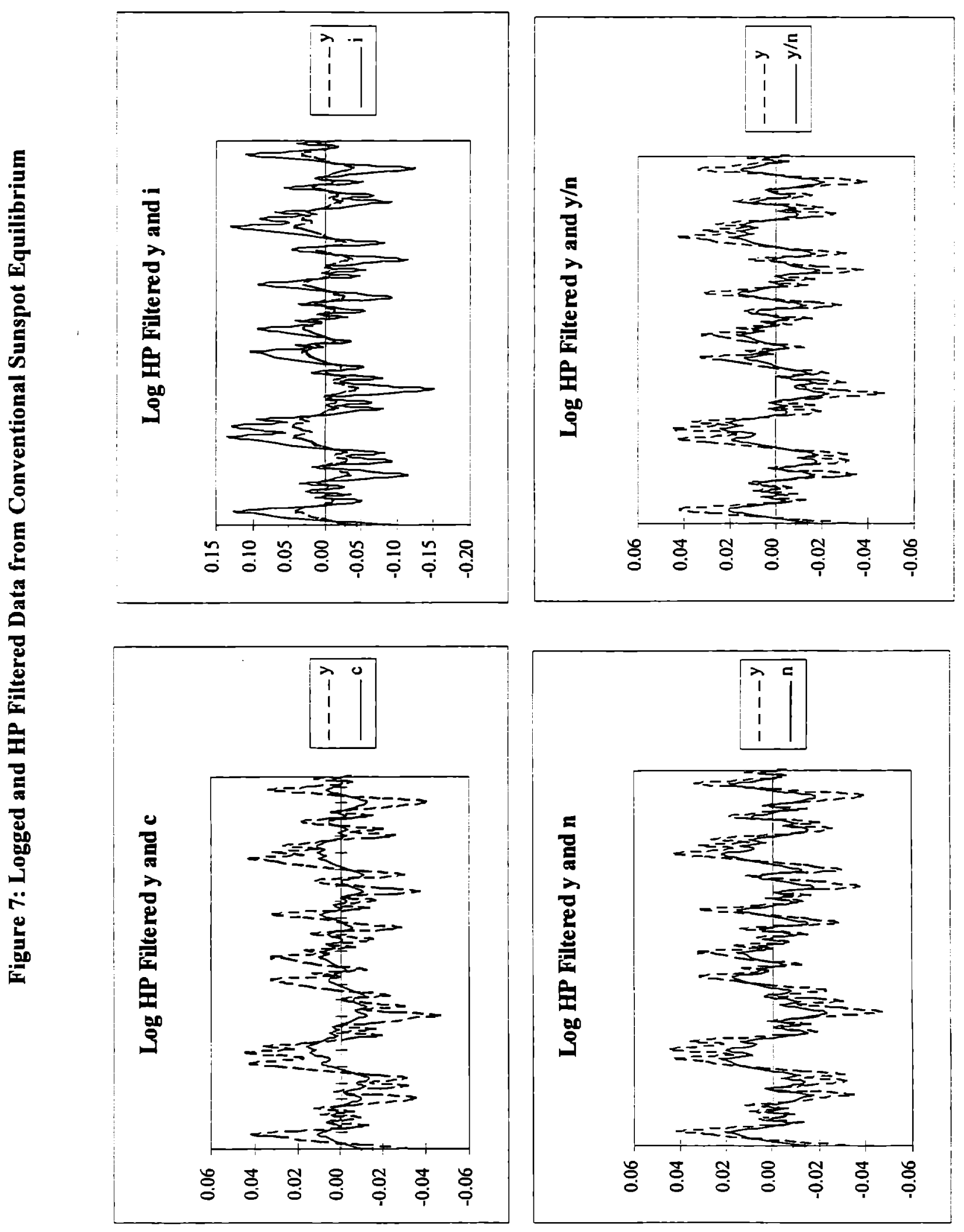


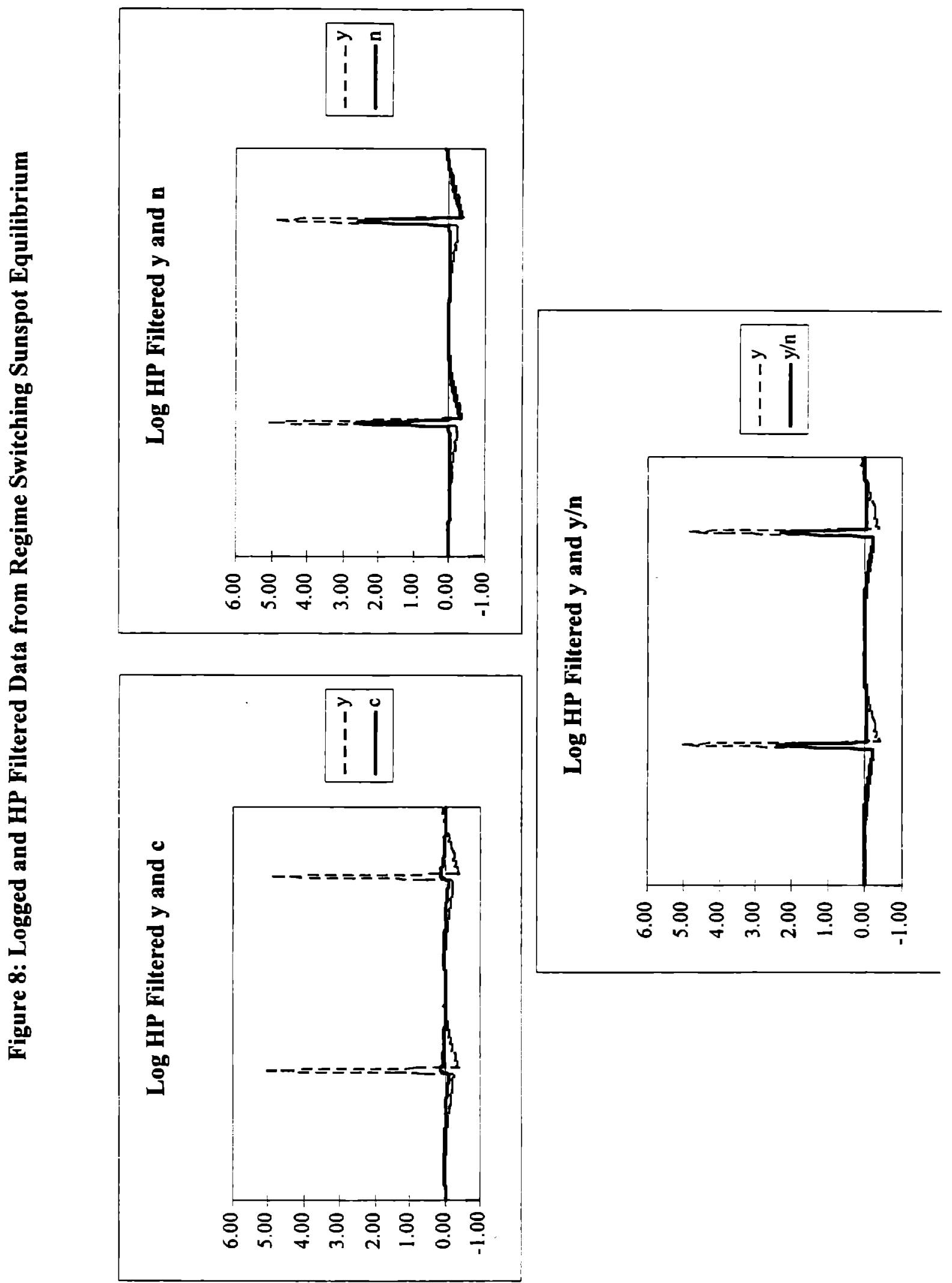


Figure 9a: U.S. Data, Time Worked

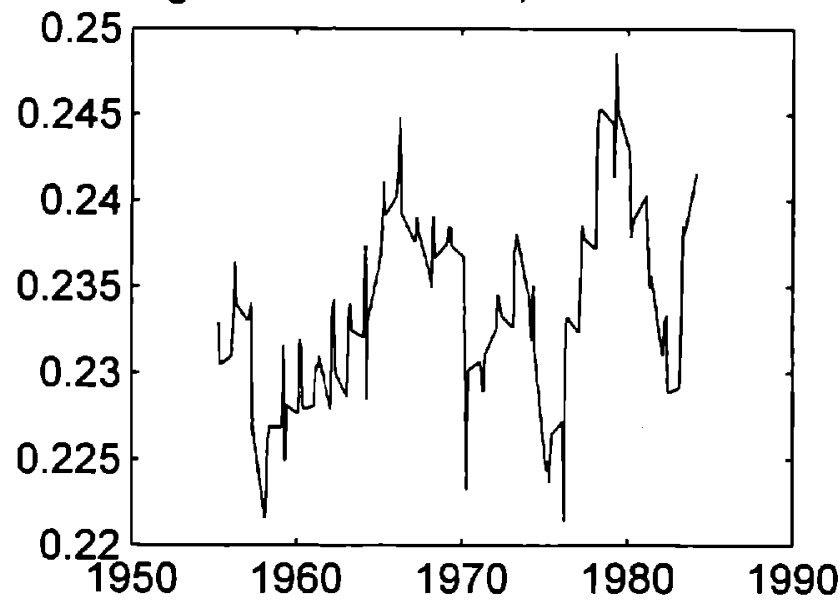

Figure 9c: Scatter Plot

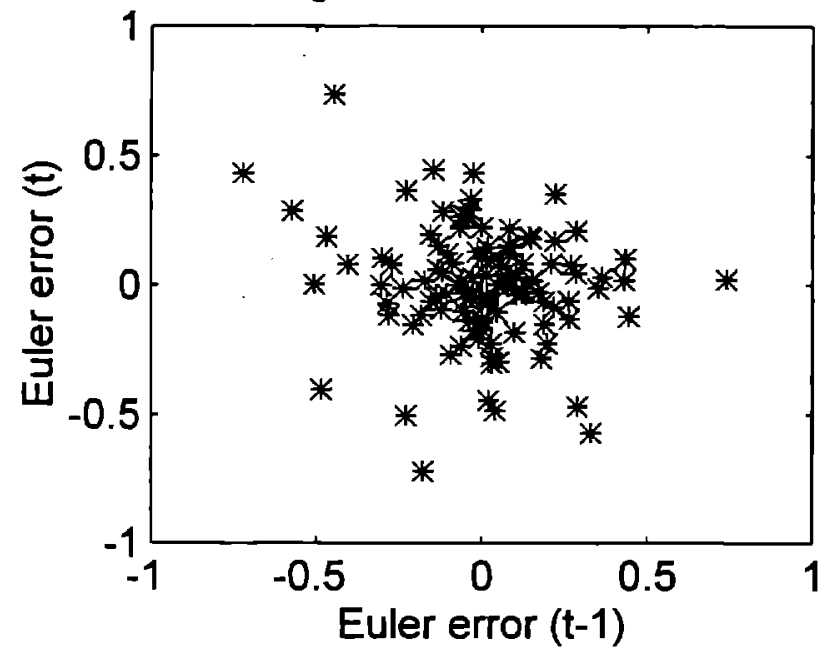

Figure 9b: Euler Errors

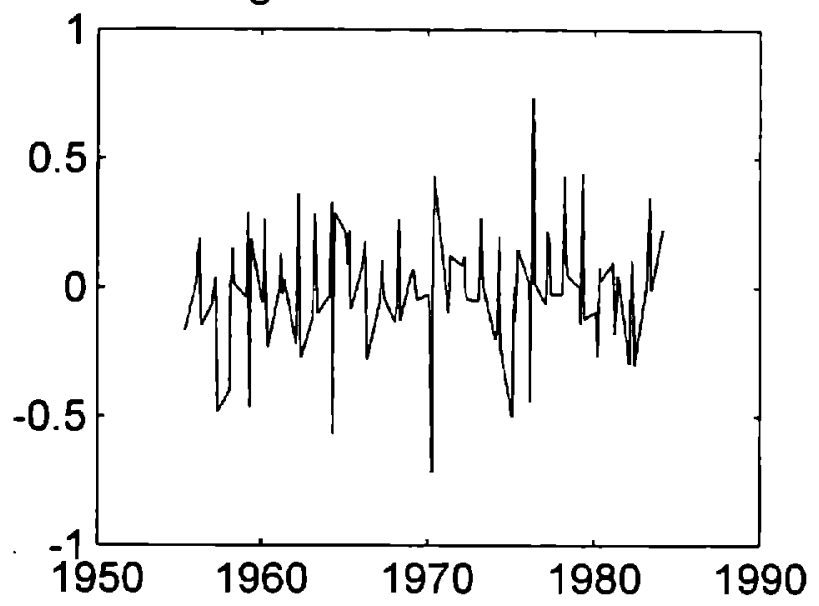

Figure 9d: Scatter Plot

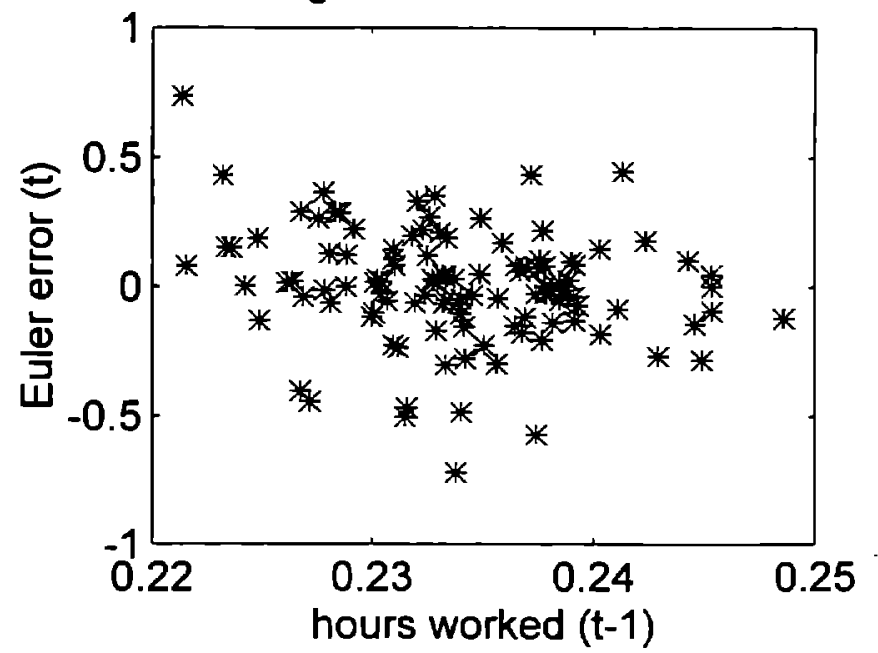


Figure 10: Hours Worked Versus Output Per Unit of Capital

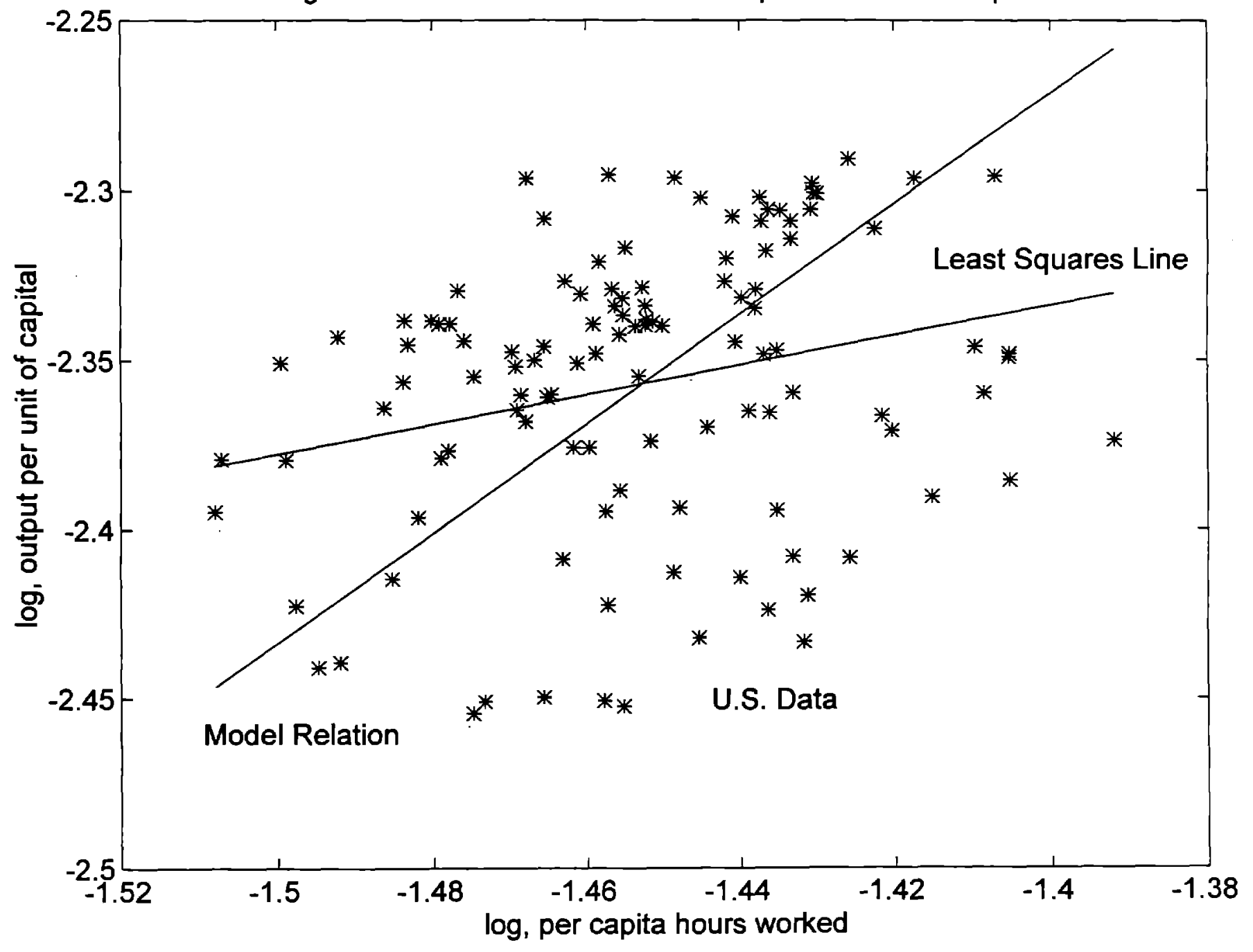


Figure 11: Euler Equation, $v\left(n, n^{\prime}\right)=0$, for Taxed and Untaxed Economies

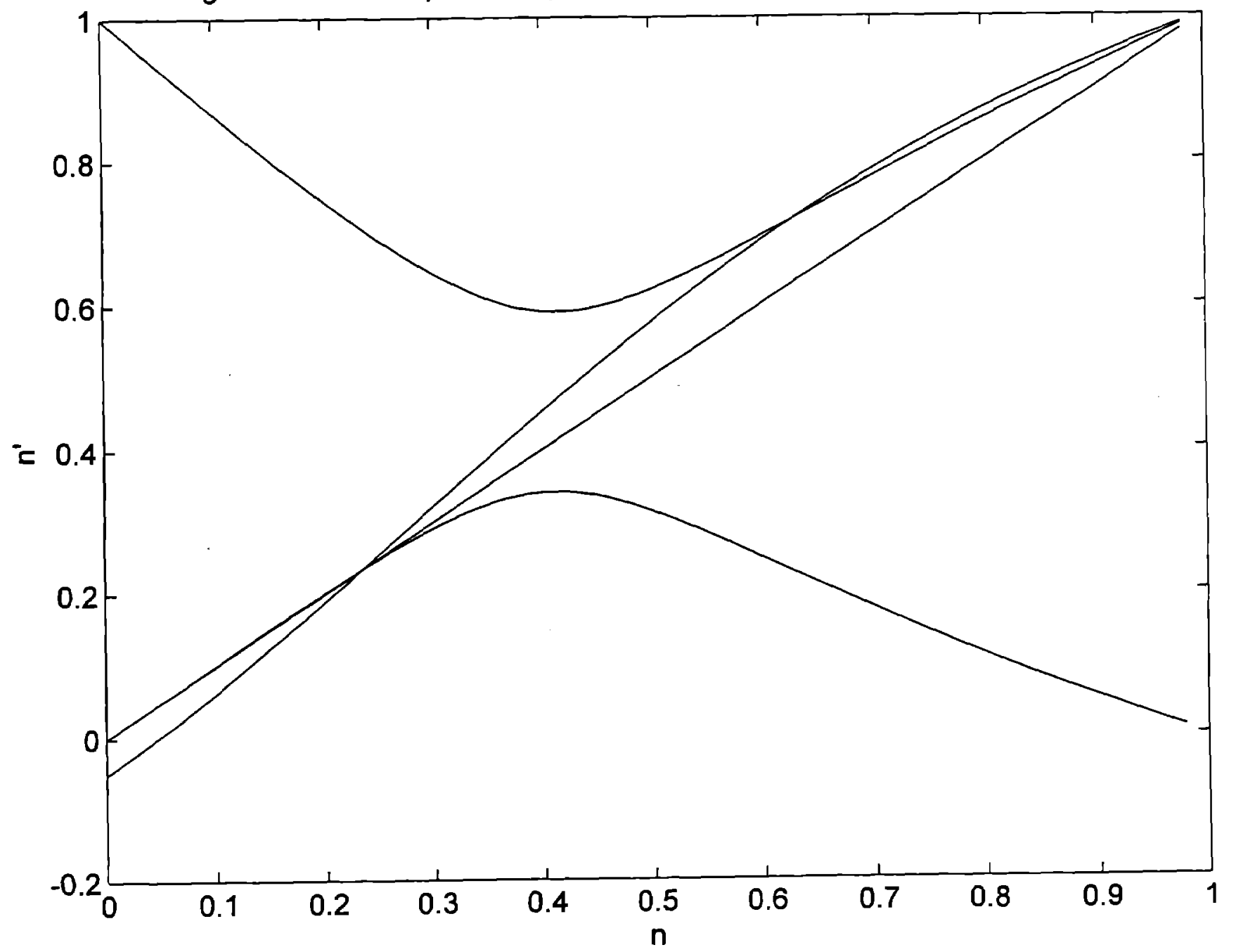


Figure 12a: $v\left(n, n^{\prime}\right)=0$, With Income Tax Rate $=-2$
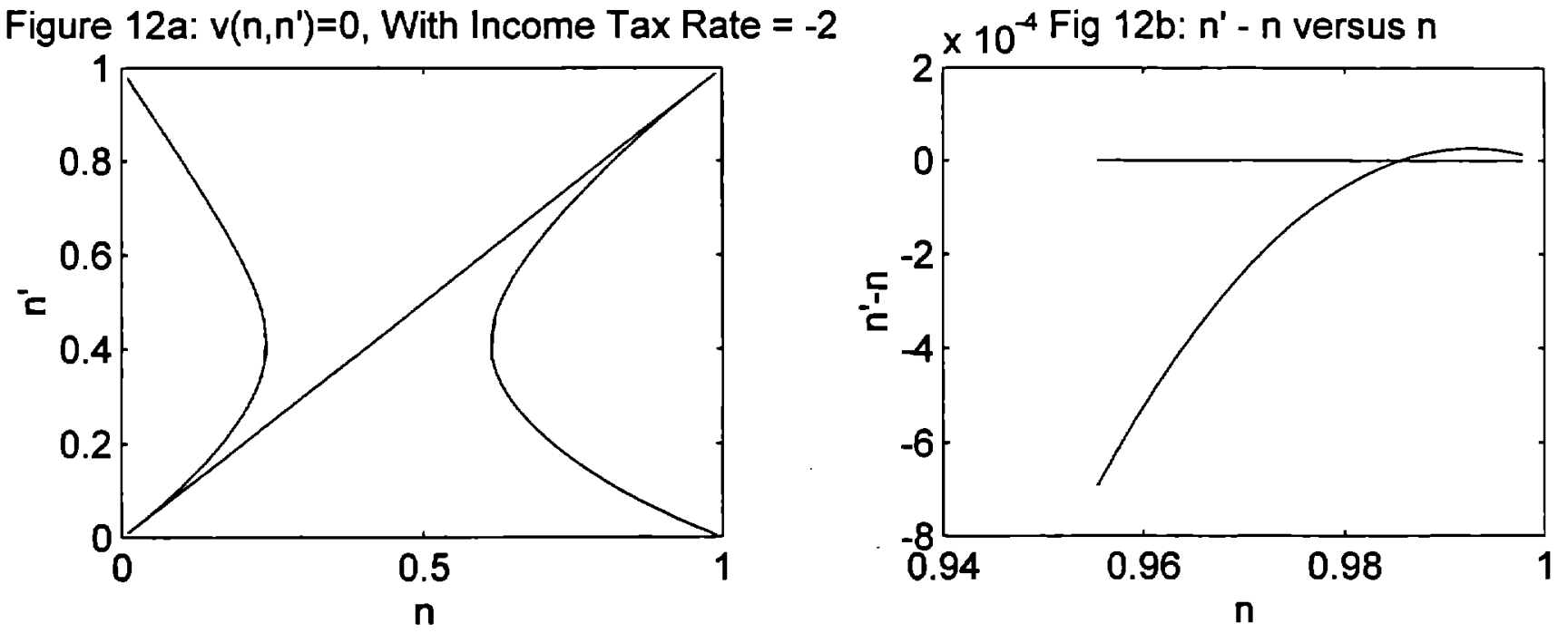

Figure $12 c: n '-n$ versus $n$

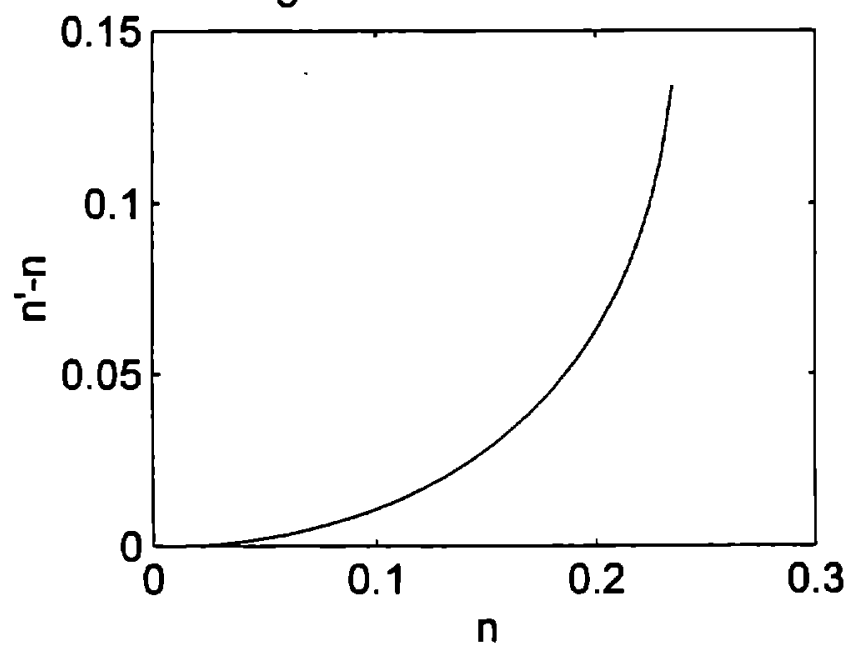

